Ministry of Education Iraqi Directorate of Education Baghdad Karkh III

First Conference Department of Preparation and Training Division of Research and Studies

وزارة التربية العراقية مديرية تربية بغداد الكرخ الثالثة الهؤتمر الاول قسم الاعداد والتدريب شعبة البحوث والدراسات

\title{
The impact of cognitive behavioral therapy with program (Self-Instructions)
}

\author{
Waffa Shakir Abdul Al-kareem \\ Al - Qasim Green University, Babylon, Iraq \\ Wafaa.shakeer@gmail.com
}

\begin{abstract}
The research aims to identify the effect of behavioral cognitive therapy on with(selfinstruction by Meichenbaum)in psychologic and social rehabilitation of patients with residual schizophrenia at(Ibn-Rush Hospital for psychologic diseases)Baghdad, in order to achieve the aim of research, also the static analysis sample has been used that consist of(120)patients with residual schizophrenia, one case has been diagnosed which get lowest degrees for applying the program on it, also build a therapy program according to the presented problem on the scale. after the therapy program has finished with individual therapy method on sample, the results show that program is effective in psychologic and social rehabilitation.
\end{abstract}

Keywords: cognitive therapy, Meichenbaum, rehabilitation, residual schizophrenia.

\section{تأثير العلاج السلوكي المعرفي بأسلوب (التعليمات الذاتية) في التأهيل الذفسي والاجتماعي لمرضى الفصام المتبقي}

\author{
وفاء شاكر عبد الكريم \\ جامعة القاسم الخضراء، بابل، العراق \\ Wafaa.shakeer@gmail.com
}

المستخلص يستهدف البحث الحالي التعرف على تأثير العلاج السلوكي المعرفي بأسلوب(التعليمات الذاتية) للعالم ميكنبوم في إعادة التأهيل النفسي والاجتماعي لمرضى الفصام المتبقي المراجعين الى(مستشفى ابن رشد للأمراض النفسية) بغداد، وقد تناولت الباحثة اطاراً نظرياً شمل كل متغيرات البحث، وتحقيقاً لهدف البحث تم بناء مقياس التأهيل النفسي الاجتماعي، ثم الاستعانة بعينة التحليل الاحصائي البالغة(120) مصاباً بالفصام المتبقي وتم تشخيص حالة واحدة ممن حصلت على ادنى الدرجات لتطبيق البرنامج عليها، وكذلك بناء البرنامج العلاجي وفق المشكلات المطروحة في المقياس وبعد الانتهاء من تطبيق البرنامج العلاجي بأسلوب العلاج الفردي على عينة البحث، أظهرت النتائج أن البرنامج كان فاعلاً في اعادة التأهيل النفسي والاجتماعي.

الكلمات الدالة: العلاجي المعرفي، ميكنبوم، التأهيل، الفصام المتبقي.

Abdul Al-kareem, W. (2019). The impact of cognitive behavioral therapy with program (Self- Instructions). Journaı Port Science Research, 2(3), 537-565. doi.org/10.36371/port.2018.02.3.11. 
يقصد بالتأهيل النفسي الاجتماعي عملية مساعدة الافراد على الوصول الى الحالة التي تسمح لهم بأن ينهضوا بما تتطلبه المواقف المحيطة بهم للوصول إلى حاله من التواؤم والانسجام بين الفرد ونفسه وبينه وبين بيئته وتبدو في امكانيته على ارضاء اغلب حاجاته وتصرفه تصرفا مرضيا ازاء مطالب البيْه المحيطة به [1], وتعد الاضطرابات النفسية والعقلية من اشد العوامل قسوة وعنفا في انتزاع سعادة الانسان وتدميرها وكذلك سعادة وامن المحيطين به ايضا ، فالأسرة التي يصاب احد اعضائها بالاضطراب النفسي تعاني من التعاسة و البؤس وضيق الصدر ، فضلا عما يسببه المرض من اعاقة الإنتاجية للفرد .

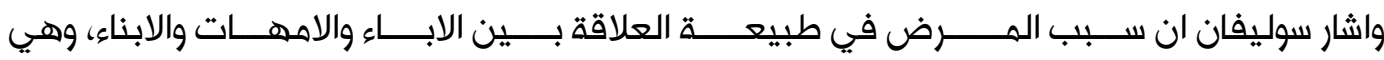
علاقــــــ قد تكـــــون مانعه لتكوين حاله من التقدير الذي يشعر به الفرد نحو نفسه، وكذلك في حالة الرعب التي يمكن ان يشعر بها الفرد نتيجة ذلك الارتباط الشعوري [2]. وان المشكلة الحقيقية للفصام المتبقي لا تكمن في الاعراض الحاده التي تتمثل في الهياج والثورة والسلوكيات العنيفة والتي تسمى بالأعراض الموجبة لمرضى الفصام التي تختفي عن طريق العلاج الدوائي, بل المشكلة الاكبر في الاعراض السالبة والتي تسهى بـ (الفصام المتبقي) هذه الاعراض لا تستجيب للعلاج الدوائي, وينبغي ان تعالج بأساليب العلاج الذفسي, وتعد هذه الاعراض اكثر خطورة وتأثير في حياة المريض اذ لا تلقى لقى الاهتمام والعناية الكافية في كثير من الحالات اذ تتسم بالخمول والانسحاب ولا يحدث خلالها الهياج الشديد او الثورة والانفعالات الحادة التي تجذب الانتباه وتحرك الاهتمام, وان الخصائص الشخصية للفرد المصاب اضرار جسيمه على الفرد واسرته ، لذا ارتأت الباحثة القيام بهذا البحث وذلك من خلال ما شاهدته اثناء تواجدها في (مستشفى أبن رشد الامراض النفسية -بغداد) على اقتصار العلاج على الادوية دون الاهتمام بالعلاج النفسي الذي يعد مكملا واساسيا مع العلاج الدوائي. وتباينت الدراسات في مدى تأثير أسلوب التعليمات الذاتية للعالم ميكنبوم في عدد من المتغيرات التابعة على عينات مختلفة لذا يمكن للباحثة ان تلخص مشكلة البحث من خلال الاجابة عن السؤال الآتي: ما مدى تأثير العلاج السلوكي المعرفي باسلوب التعليمات الذاتية للعالم ميكنبوم في التأهيل النفسي والاجتماعي لدى مرضى الفصام المتبقي.

\section{أهمية البحث}

ان الاهتمام بالصحة الفسية يعني الاهتمام بالفرد وتكامله، وبالمجتمع وتفاعله، لان الصحة النفسية تهم الفرد والمجتمع، فهي تساعد الفرد على تسهيل انسياب حياته النفسية وجعلها أقل عرضة للتوترات والصراعات وتجعله أكثر حيوية ومثابرة، كما تساعده على سرعة الاختيار واتخاذ القرار

عبد الكريم، وفاء شاكر. (2019). تأثير العلاخ السلوكي المعرفي بأسلوب (التعليمات الذاتية) في التأهيل النفسي

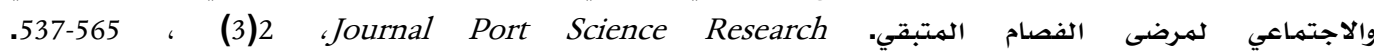


وتساعده على فهم نفسه والأخرين من حوله [3] لذا فان الصحة النفسية لا تقل اهمية عن الصحة الجسمية العامة، وان الاهتمام بها تعبير عن الاهتمام بالصحة العامة "فلا غنى للجسم عن صحة النفس، ولا غنى للنفس عن صحة الجسم. [4] ويسعى العلاج النفسي الى اعادة التأهيل النفسي والاجتماعي للفرد المصاب بالاضطراب النفسي ، من خلال برامج مقصودة ومنظمة يساهم فيها المختصين في العلاج السلوكي المعرفي. ويعد انموذج ميكنبوم (Meichenbaum) من بين ثلاثة انموذجات اساسية لها الريادة في مجال العلاج السلوكي المعرفي هي انموذج بيك Beek الذي يعرف الاتجاه الاستدلالي وانموذج ميكنبوم (Meichenbaum) وانموذج أليس Ellisi [5]. اذ يؤكد هربرت ميكنبوم على اهمية الحديث الداخلي عند الانسان وتأثيره على العمليات الادراكية، وكيف يمكن من خلاله تغيير التفكير والمشاعر والذي يؤدي في النهاية الى التقليل من تلقائية السلوك غير المتوافق ويعطي الاساس الذي يبني عليه سلوكاً جديداً متوافقاً [6]. وكذلك ركز على اهمية اللغة والتعليمات اللفظية على توجيه وتغيير السلوك معتمد بذلك على اساس ان ما يقوله الفرد انفسه هو العامل الاساس في توجيه السلوك، وبذلك استعمل ميكنبوم التعليمات الذاتية التي تعتمد على تدريب حالات الفصام على مجموعة من الخطوات تشتهل على تعليمات لفظية يقولونها لأنفسهم تعمل على تعديل السلوك وتغييره [7]. وعلى المعالج ان يساعد المتعالج في اختيار السلوكيات المناسبة وعلى وفق الافكار الجديدة التي يحملها الحديث الذاتي [8]. مما تقدم يدل على ان بحوث الصحة النفسية والعلاج النفسي بشتى مستوياتها الارشادية والوقائية والعلاجية اصبحت ذو اهمية كبيرة خاصة في ظل الحياة المعاصرة التي تتسم بالتعقيد ومتطلبات العمل المعاشي وتنافساته [9].

\section{وبناءاً على ما ذكر يهكن تلخيص أهمية البحث الحالي بالنقاط الآتية:}

1) أهمية الصحة الذفسية للفرد والمجتمع إذ أن الأفراد والمجتمعات الذين يتمتعون بالصحة النفسية يكونون أكثر شعوراً بالسعادة وأكثر عطاءًا وانتاجاً. 2) أهمية العلاج السلوكي المعرفي في علاج كثير من الاضطرابات والأفكار السالبة. 3) أهمية أسلوب التعليمات الذاتية للعالم مكينبوم في علاج عديد من الاضطرابات النفسية والافكار السلبية الخاطئة وهذا ما أكدته العديد من الدراسات السابقة.

4) اهمية التأهيل النفسي والاجتهاعي للمصابين باضطراب الفصام المتبقي لأهميته في إعادة

$$
\text { تأهيلهم واندماجهم بالمجتمع. }
$$

5) أهمية دراسة الافراد والهصابين باضطراب الفصام المتبقي كونهم شريحة مؤهلة للاندماج مع المجتمع إلا ان النظرة السلبية والخاطئة تجاههم تجعلهم شخصيات تجنبيه ولديهم اعراض سالبة نحو الأفراد والمجتمع فمن الضروري دراسة هذه الشريحة وإعادة تأهيلهم نفسياً واجتماعياً.

Abdul Al-kareem, W. (2019). The impact of cognitive behavioral therapy with program (Self- Instructions). Journaı Port Science Research, 2(3), 537-565. doi.org/10.36371/port.2018.02.3.11. 
1) قياس التأهيل النفسي والاجتماعي لدى المرضى المصابين بالفصام المتبقي. 2) معرفة تأثير العلاج السلوكي المعرفي بأسلوب (التعليمات الذاتية) في التأهيل النفسي والاجتماعي لدى المصابين بالفصام المتبقي ويتحقق ذلك من خلال الفرضية الصفرية الآتية:

لا توجد فروق ذات دلالة احصائية في التأهيل النفسي والاجتماعي لدى الهصابين بالفصام المتبقي قبل تطبيق البرنامج العلاجي (وفق أسلوب ميكنبوم) واثناءه وخلال مدة المتابعة (Follow up) لمتعالج واحد.

\section{حدود البحث}

يقتصر البحث الحالي على عينة من المضطربين المصابين بالفصام المتبقي في مستشفى ابن رشد التدريبي للأمراض النفسية للعام (2015-2016)

\section{تحديد الهصطلحات}

اولاً: تأثير Effect عرفه الحنفي (1991) بأنه مقدار التغيير الذي يطرأ على المتغير التابع بعد تعرضه لتأثير المتغير المستقل [10]. ثانياً: العلاج السلوكي المعرفي Congintive Bahavoir Therapy ميكنبوم 1992 (Michenbaum) بأنه أساليب اعادة تكوين التراكيب والبناءات المعرفية لدى الفرد، فالحوار الذاتي الداخلي والافكار الايجابية التكيفية التي يجب أن يتدرب عليها الفرد ويعلم مهارات معرفية للتكيف مع المشكلات، وتكوين حلول عدة لها واختيار الحل الهناسب [11]. ثالثاً: التعليمات الذاتية ميكنبوم (Meichenbaum, 1974) يقصد به الأحاديث الذاتية التي تأتي من آلية النشاط السلوكي غير المتوافق التي تزودنا الاساس لاكتساب الافراد القدرة على ضبط سلوكهم الشخصي من خلال تعليمات صريحة يقولونها لأنفسهم تتحول فيما بعد الى تعليمات داخلية ضمنية تؤدي الى سلوك جديد متوافق [12]. التعريف الاجرائي فهو مجموعة التقنيات والاجراءات السلوكية المعرفية التي وضعها العالم (ميكنبوم) واستعملتها الباحثة لتغيير الأحاديث السلبية لدى المصابين بالفصام المتبقي وفقاً

عبد الكريم، وفاء شاكر. (2019). تأثير العلاخ السلوكي المعرفي بأسلوب (التعليمات الذاتية) في التأهيل النفسي

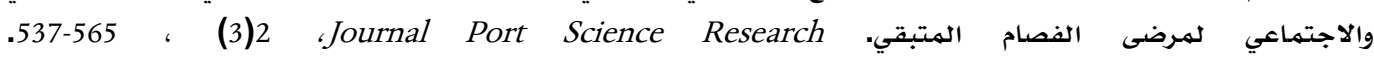


لمقياس التأهيل النفسي والاجتماعي، والذي يقاس اجرائياً بالدرجة والفرق بين الاختبارين القبلي والبعدي على مقياس التأهيل النفسي والاجتماعي لكل فرد.

\section{خامساً التأهيل الذفسي والاجتماعي (the psychological and social rehabilitation)} سوليفان (1987) عملية ديناميكية تقوم على اساس العلاقات الشخصية المتبادلة التي يقيمها الفرد هع الاخرين يسعى من خلالها الى اشباع حاجاته الاولية من جهة والى تحقيق حاجاته الى الامن والطمأنينة من جهة اخرى بما يؤدي الى شعوره بحالة من التوافق والانسجام هع نفسه وهع الاخرين

سادساً: الفصام المتبقي residual schizophrenia عرفه: زهران (1978) يتمثل بوجود باقي افكار او انفعالات او سلوك فصامي وبقايا هلوسات وهاءات بسيطة لا تؤثر في توافقه الاجتماعي [14].

الحبيب، (2013) وهو النوع الذي يطلق على الاعراض المتبقية لدى مريض الفصام بعد زوال الاعراض

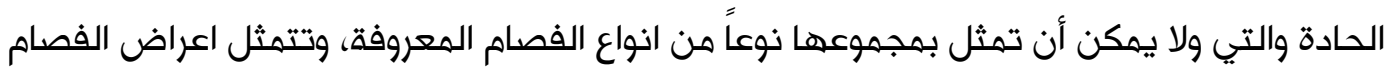
المتبقي في جمود والمشاعر، والعزلة الاجتماعية، والسلوك الغريب، والافكار غير المنطقية، وشيء من انعدام ترابط الكلام عند المريض [15]. اما التعريف المعتمد في البحث الحالي هو تعريف (زهران 1978) لأنه يعد أنسب التعاريف التي يمكن الاعتماد عليها لدى عينة البحث الحالي.

\section{الإطار النظري}

العلاج السلوكي المعرفي: يعد العلاج السلوكي المعرفي اتجاها علاجيا حديثا نسبيا يعمل على الدهج بين العلاج المعرفي بفنياته المتعددة والعلاج السلوكي بما يضهه من فنيات ، ويعتمد الى التعامل مع الاضطرابات المختلفة من منظور ثلاثي الابعاد اذ يتعامل معها معرفياً وانفعالياً وسلوكياً ، ويعتمد الئ هذا الاتجاه العلاجي على الاقناع الجدلي التعليمي بما يضمنه من فنيات عديدة في تقديم منطق العلاج وشرحه للمريض واقناعه بضرورة الالتزام في العلاج وقيامه بالدور الهناط به ، وتوضيح العلاقة بين الافكار المشوهة والاعتقادات اللاعقلانية من ناحية وبين ما يعاني المريض من سواء ذلك في

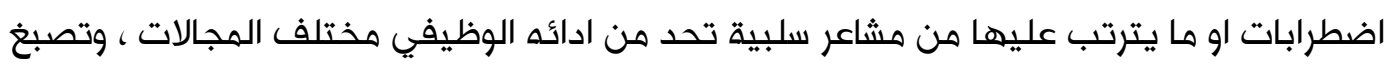
هذا الاداء بالخلل [16].

لذا يجب ان تعتمد سياسة العلاج النفسي على تغيير مفاهيم المريض واعادة تشكيل مدركاته حتى يتيسر له التغيير في سلوكه اذ يرى هذا الاتجاه ان الاضطراب النفسي عندما يحدث لا يشمل جانبا

Abdul Al-kareem, W. (2019). The impact of cognitive behavioral therapy with program (Self- Instructions). Journaı Port Science Research, 2(3), 537-565. doi.org/10.36371/port.2018.02.3.11. 
واحدا من الشخصية فحسب، بل يمتد ليشمل اربعة جوانب هي السلوك الظاهر (الافعال الخارجية)، والانفعال (التغيرات الفسيولوجية)، والتفكير (طرق التفكير والقيم)، والتفاعل الاجتماعي (العلاقات بالأخرين) [17]. وان مهاجمة الافكار السلبية تعد وسيلة للوصول الى النهاية وليست هي النهاية في حد ذاتها فهدف العلاج هو ايجاد حلول لمشكلات المريض باستعمال استراتيجيات سلوكية معرفية فضلا عن مساعدة المريض في ان يفكر بشكل أكثر عقلانية [18]. وان هدف العلاج السلوكي المعرفي هو مساعدة المعالج في تعلم طرائق جديدة لحل مشكلاته فالمعالج هنا لا يستطيع ان يحل للمتعالج كل مشكلة تزعجه، ان الفرد المتعالج هنا بمعنى (يتعلم كيف يتعلم) [19].

\section{نظريات العلاج السلوكي المعرفي}

تعديل السلوك المعرفي دونالد هربرت ميكنبوم (meichenbaum Donald) ادت الخبرات التي عاشها ميكنبوم في تدريبه مع المرضى الفصاميين وغيرهم فيما اذا كان من الممكن تدريبهم على ان يتحدثوا الى انفسهم بطريقة تؤدي الى تغيير سلوكهم، وركز بذلك ميكنبوم على حديث الذات في محاولة لتغييرها وكذلك اهتم بالتخيلات لمعرفة اذا كانت مثل هذه التغيرات ستؤدي الى تغيرات في التفكير وفي الشعور والسلوك. وقد ادى استعمال هذه الطريقة مع طرق الاشتراط الاجرائي الى اعطاء نتائج أفضل، واستنتج ميكنبوم من هذه البحوث الى ان التدريب على التعليمات الذاتية يمكن ان يكون فعالا في تغيير الانماط المعرفية، وكذلك الخاصة بعزو السلوك [20].

وقد استعمل ميكنبوم طريقة بعد ذلك في تدريب حالات الفصام على تعديل سلوكهم اذ اشتملت التعليمات اللفظية التي يقولونها لانفسهم على النقاط الاتية:

1) اعادة صياغة مطالب المهمة او الواجب. 2) تعليمات (ارشادات) بأداء المهمة ببطء وان يفكر قبل التصرف. 3) اسلوب معرفي باستخدام التخيل في البحث عن حل.

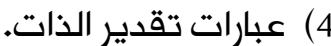
5) مثال لاستجابة ضعيفة او خاطئة يتبعها سبب عدم وملاءمتها. 6) عبارة تصف كيفية التعامل مع الفشل وكيفية الوصول الى الاستجابة المناسبة. وتقوم فكرة التدريب على التعليمات الذاتية على فرض مؤداه (أن الاشياء التي يقولها الناس لأنفسهم تحدد باقي الاشياء التي يفعلونها، فسلوك الانسان يتأثر بالجوانب المختلفة لأنشطته والتي توجه بتكوينات متنوعة مثل الاستجابات الفيزيولوجية، وردود الفعل الوجدانية، والمعارف (الجوانب المعرفية) والتفاعلات الاجتماعية (الخاصة بالعلاقات مع الاخرين)، ويعد الحديث الداخلي أحد هذه الانشطة او التكوينات [21].

عبد الكريه، وفاء شاكر. (2019). تأثير العلاخ السلوكي المعرفي بأسلوب (التعليمات الذاتية) في التأهيل النفسي

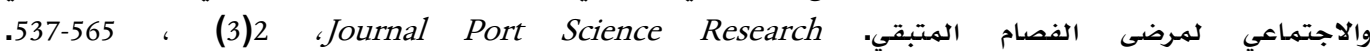


ويقوم انهوذج هيكنبوم (meichenbaum) على ادخال مجموعة من التعليمات الذاتية التي تحل محل الافكار الا توافقية ويفترض ميكنبوم (meichenbaum) ان تدريب المرضى على الحوار الذاتي يمكن ان يؤدي الى تغيير سلوكهم وبالتالي يؤدي الى ضبط السلوك والتخفيف من الضغط النفسي والتأثير على الحالة الانفعالية للفرد [22]. وتشتمل عملية العلاج وفق انموذج هيكنبوم على ثلاث مراحل اساسية

المرحلة الاولى مراقبة الذات او الملاحظة الذاتية (self - observation) وهنا تحدث عملية احلال افكار جديدة متكيفة محل افكار قديمة غير متكيفة، ان اعادة تكوين المفاهيم (redoctronizaion) تساعد على اعطاء معان جديدة للأفكار والمشاعر والسلوكيات [23]. المرحلة الثانية السلوكيات والافكار غير الهتكافئة: incompatible thoughts and behaviors: في هذه المرحلة تكون عملية المراقبة الذاتية عند الهتعالج قد تكونت واحدثت حوارا داخليا عنده، ان ان المان هذا الحديث الجديد يؤثر في الابنية المعرفية لدى المتعالج، وأن الحديث الجديد يتسبب في البرهجة الذاتية، إذ أن بإمكاننا أن نغير البرهجة السلبية واحلال برهجة أخرى جديدة ايجابية تزودنا بالقوة، عندما نتحكم بأفكارنا، ولكن هذا التغيير يعتمد على شخصية الفرد [24]. المرحلة الثالثة المعرفة المرتبطة بالتغيير cognitive concerning change وتتعلق هذه المرحلة بتأدية المتعالج لههمات تكيفية جديدة خلال الحياة اليوهية والتحدث مع المتعالج حول نتائج هذها الاعمال، ويرى هيكنبوم انه ليس الههم ان يركز المتعالج نفسه حول السلوكيات المتغيرة التي تعملها وعلى نتائجها التي سوف تؤثر على ثبات وتعميم عملية التغيير في السلوك فقط بل ينبغي على الى العان المعالج ان يهتم بالعمليات الاساسية الثلاثة هي: (3) السلوك الناتج عن ذلك [25]. (1) البناعات المعرفية. الحوار الداخلي. التأهيل النفسي والاجتماعي مفهوم التأهيل يعني الانسجام والهؤازرة، المشاركة، التضامن واجتماع الكلمة وهذه كلها تقارب التهاب المصطلح الاجنبي (Confority) ويعني التأليف والتقارب فهو نقيض التخالف والتنافر والتصادم [26]. والتأهيل في البحوث النفسية والصحة النفسية تعني العملية الهتفاعلة والمستمرة يمارسها الفرد

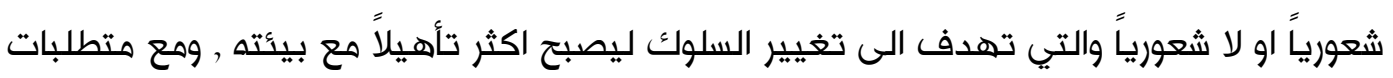

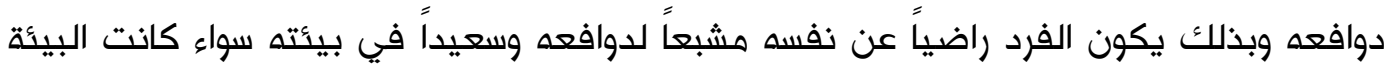
طبيعية في ظروفها المناخية او الثقافية او النفسية او الاجتماعية او التربوية والصحية وان مفهوم التأهيل يعني القدرة على اقامة علاقات اجتماعية مثمرة وهمتعة تتميز بقدرة الفرد على الحب البه 
والعطاء من جهة , وهن جهة اخرى هو القدرة على العمل المنتج الفعال الذي يجعل الفرد يرمز الى حالة معينة من النضج يصل اليها [27].

\section{نظرية العلاقات الشخصية المتبادلة}

هاري ستاك سوليفان تظهر الشخصية الانسانية وفقاً لوجهة نظر سوليفان من القوى الشخصية والاجتماعية التي تؤثر على الفرد من ميلاده واما بناء الشخصية النهائي فهو نتيجة التفاعل هع الكائنات الانسانية الاخرى. وأكد أن تنظيم الشخصية يتكون من الوقائع المتبادلة بين الاشخاص، وليس من الوقائع الشخصية الداخلية، ويعد سولفيان الشخصية مركزاً ديناميكياً لعمليات عديدة تحدث في سلسلة من المجالات الشخصية المتبادلة ويرى بأن هذه العمليات الديناميكية هي نظام الذات والتشخيصات [28] وقد قامت نظرية سوليفان على عدد من المبادئ والافتراضات هي: العلاقات الشخصية المتبادلة، نظام التوتر وتحولات الطاقة [29]. وأكد سوليفان ان طبيعة الشخصية تحددها

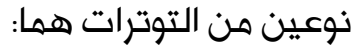

1) التوترات الداخلية التي تنشأ من الهصادر الفسيولوجية. 2) التوترات الخارجية التي تنشأ من المصادر الاجتماعية.

وتترتب هذه الحاجات في نظام هرمي يمكن اشباعها بالتدريج وأن الاخفاق الطويل في عدم اشباع هذه الحاجات يؤدي الى سوء التأهيل النفسي والاجتماعي [30]. فالتوتر النفسي الداخلي يحدث نتيجة تفاعل الفرد في عمليات العلاقات الشخصية المتبادلة اذ يحدث اثناء هذا التفاعل عملية اشباع حاجات الفرد او زيادة التوتر لعدم اشباعها، لذا نجد الفرد يسعى لإشباع حاجاته الاولية من جهة وحاجاته الى الامن والطمأنينة من جهة اخرى. وأما التوتر النفسي الخارجي ينتج عن اخطار موهوهة او حقيقية تهدد احساس الفرد بالأمن الاجتماعي وزيادة هذه الاخطار تؤدي الى ضعف قدرة الفرد على اشباع الحاجات واضطراب العلاقات الشخصية المتبادلة انعدام الامن الاجتماعي واختلال علاقاته المتبادلة نتيجة انعزاله فستكون شخصيته مضطربة تؤدي به الى سوء التأهيل الاجتماعي، اذ ان عملية التفاعل في الموقف تؤدي الى خلق اهداف وعلاقات جديدة ويؤدي الى نوع محدد من اشكال السلوك، وان الهدف الاول للسلوك هو تقليل هذه التوترات بما يحقق التأهيل النفسي والاجتماعي.

ووضع سوليفان لنمو الشخصية عدة مراحل وهي مرحلة الحضانة، مرحلة الطفولة، مرحلة الحداثة، مرحلة المراهقة وفي هذه المرحلة يسعى الفرد الى انشاء علاقات اجتماعية مع الآخرين وتقويتها ويزداد نشاطه نحو تحقيق التأهيل النفسي والاجتماعي، مرحلة النضج وتتضمن هذه المرحلة بالنضج الجنسي الكامل، كما تتميز بالاستقرار وتكوين الاتجاهات الثابتة ازاء المواقف والعالم. والديناهية عبد الكريم، وفاء شاكر. (2019). تأثير العلاخ السلوكي المعرفي بأسلوب (التعليمات الذاتية) في التأهيل النفسي المئي

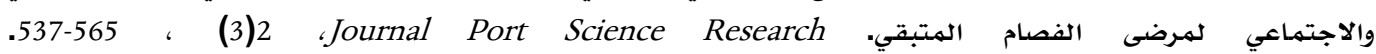


الذاتية يكمل نموها وتتبلور (للأفضل او الاسوأ) خلال هذه الفترة، وإذا تمكن الفرد من تجاوز المراحل السابقة بشكل طبيعي يكون الفرد ناضجاً ومتطبعاً اجتماعياً ومستعداً لتحمل مسؤولياته ويتمتع بالتأهيل النفسي والاجتماعي [31]. وقد تبنت الباحثة نظرية هاري سوليفان في العلاقات الشخصية

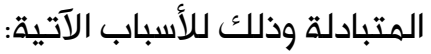

1) ان نظرية سوليفان هي أحد نظريات الاتجاه النفسي الاجتماعي الذي أكد على اهمية العلاقات الشخصية المتبادلة في اشباع الاولية والنفسية وعدم اشباعها يؤدي الى التوتر وسوء التأهيل

$$
\text { النفسي والاجتماعي. }
$$

2) أكد على اهمية الاسرة في التنشئة الاجتماعية للطفل واهمية الام في اشباع الحاجات الاولية

$$
\text { والنفسية للطفل. }
$$

3) أكد على اهمية السنوات الخمس الاولى في التأهيل النفسي والاجتماعي في المراحل اللاحقة هن

$$
\text { حياة الفرد. }
$$

4) قسم الشخصية الى عدة مراحل ولكل مرحلة خصائص معينة تختلف عن المراحل اللاحقة لها وهرتبطة معها وتؤثر بعضها في البعض الآخر في التأهيل النفسي والاجتماعي للفرد.

\section{Residual Schizophrenia الفصام المتبقي}

يكون هذا الاضطراب على شكل نوبة واحدة على الاقل من الفصام يجري فيها تفاقم واضح من مرحلة مبكرة (تتضمن نوبة او أكثر من الاعراض الذهنية التي تستوفي المعايير العامة للفصام من دون ان تسيطر على الصورة السريرية اعراض ذهانيه موجبة الى مرحلة تالية تتميز بأعراض سالبة طويلة ولكي

$$
\begin{aligned}
& \text { 1 ) اعراض سلبية } \\
& \text { أ- بطء نفسي حركي. }
\end{aligned}
$$

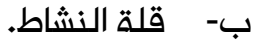

$$
\begin{aligned}
& \text { ت- تبلد الوجدان وتسطح العاطفة. } \\
& \text { ث- انعدام المبادرة وقلة الفاعلية. } \\
& \text { ج- فقر في كمية ومضمون الكلام. } \\
& \text { ح- خلل في التواصل غير اللفظي مثل تعبيرات الوجه والتقاء العيون. } \\
& \text { خ- تغير نبرات الصوت وتغيير في وضع الجسم. } \\
& \text { د- سوء العناية بالذات والمظهر الخارجي. } \\
& \text { ذ- خلل في العلاقات الشخصية والاجتماعية والمهنية. }
\end{aligned}
$$

Abdul Al-kareem, W. (2019). The impact of cognitive behavioral therapy with program (Self- Instructions). Journaı Port Science Research, 2(3), 537-565. doi.org/10.36371/port.2018.02.3.11. 
2) دليل من الماضي على وجود نوبة فصامية واحدة على الاقل تستوفي معايير الفصام.

3) وجود فترة مدتها ستة أشهر على الاقل انخفضت فيها كثافة ومعدل الاعراض الظاهرة

كالأوهام والهلوسة مع وجود متلازمة الفصام السلبي لمدة شهر على الاقل.

4) غياب الخرف (Demential) او اي اضطراب عضوي الهنشأ بالدماغ، وغياب الاكتئاب الهزمن

$$
\text { او بقاء طويل في المستشفى لتفسير الاختلالات السلبية. }
$$

وقد يكون من الضروري تشخيص الفصام المتبقي بشكل مرحلي في حالة عدم امكانية الحصول على معلومات كافية حول التاريخ السابق للمرض ومن ثم عدم امكانية التأكد من ان المريض استوفى معايير الفصام في وقت ما في الماضي [32]. ان الفصام المتبقي قد يستمر لوقت محدد، اذ يظهر كحالة تحول بين نوبة سابقة مكتملة وتحسن تام، ومع ذلك فأنه قد يستهر لسنين عديدة مع حدوث تفاقمات حادة او بدونها [33].

\section{اسباب الفصام} مقدمة: يعد مرض الفصام من أكثر الامراض في المجالات الجسمية او النفسية او العقلية تعددت فيه النظريات السببية، وان من أحد الاسباب في عدم وجود نظرية تفسر بشكل مقبول ومتكامل بسبب ان الفصام ليس مرضاً واحداً، وانما مجموعة غير متجانسة من المتلازمات المرضية، لذلك من الصعوبة الجزم بسبب واحد لهذا المرض بل هو عدة تفاعلات بيئية، وراثية، وفسيولوجية وكيميائية، لذلك يمكن جمع النظريات المفسرة لأسباب الفصام ضمن ثلاث وجهات نظر هي: الهنظور البيولوجي، المنظور البيئي، المنظور النفسي [34].

\section{أولاً الهنظور البيولوجي Biological perspective}

العوامل الوراثية تؤدي العوامل الوراثية دور رئيسي في التهيئة للإصابة بمرض الفصام , اذ اشار كلاً

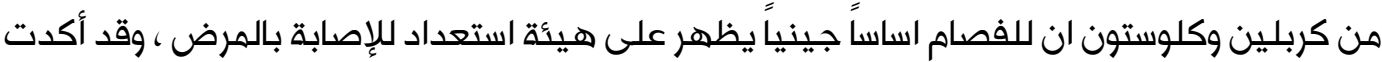
دراسات العائلة (Twins Studies) ودراسيادة (Family Studies) وداسات التوائم معدلات الاصابة بالفصام بين اقرباء المرضى المصابين مقارنة بين افراد عموم المجتمع , اذ يصل معدل الاصابة بين اخوة المريض بالفصام الى (15\%) وبين الاطفال اذا كان احد الوالدين مصاباً بالهرض الى (14\%) وتصل النسبة الى (41\%) في حالة اصابة كلا الوالدين بالفصام . ثانياً: المنظور البئي نظريات العائلة تتضمن هذه النظريات ما يأتي:

عبد الكريم، وفاء شاكر. (2019). تأثير العلاخ السلوكي المعرفي بأسلوب (التعليمات الذاتية) في التأهيل النفسي الفي

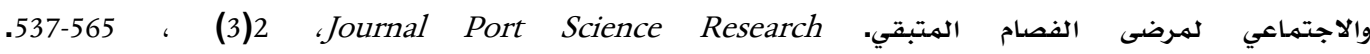


نظرية باتسون Bateson يطلق على هذه النظرية اسم الترابط الهزدوج Double Bind وترى هذه النظرية ان الفصام ينشأ من تعرض الطفل اثناء نموه لمؤثرات شديدة من الوالدين يتلقى الطفل بله رسالتين او أكثر تتميز بعدم الانسجام وبأنواع مختلفة من الاتصال.

نظرية ليدز 1963 Lidz اشتق ليدز نظريته من تطبيق التحليل النفسي على العائلة، اذ حاول ليدز تفسير العلاقة بين الوالدين ثم مع الطفل من خلال التفاعل الثلاثي بينهما، وتفترض هذه النظرية ان العائلة كلها مرضية وان الفرد المصاب ما هو الا أحد افراد هذه العائلة ويظهر اضطراب الفصام المتبقي نتيجة لعدم قدرته على التكيف مع البيئة العائلية المضطربة [35].

نظرية واين وسنجر (Wynne and singer 1965) يفترض اصحاب هذه النظرية الى وجود انماط للتفكير والاتصال بين عائلات الفصاميين، شبيهة لما يحدث في المرضى لدرجة انه يمكن التنبؤ بمرض الفرد إذا درست العائلة بكاملها [36].

نظرية الأم المولدة للفصام Schizophrenogenic mother theory: تفترض هذه النظرية ان الامهات الباردات وغير الودودات ولديهن نقص القدرة على ضبط النفس ونقص في تفهم مواقف لاقف الآخرين، يعرقلن التطور الضروري للمهارات النفسية والاجتماعية لدى الطفل مما يؤدي الى وضع اسس لس لنمط التفاعل الفصامي

\section{Social Theory النظرية الاجتماعية}

فرضية السببية الاجتماعية Social Causation تفترض هذه النظرية ان العوامل المرتبطة بكون الفرد ينتمي الى الطبقات الاجتماعية السفلى قد تسهم في اصابته بالفصام فالعزلة الاجتماعية الناجمة عن ظروف الحياة والسكن او عن ضرورات التغرب والهجرة والوحدة عامل مهم في حدوث المرض، او قد تعود الى تدني المستوى الاجتماعي والاقتصادي للفرد [37].

ثالثاً: الهنظور النفسي Psychological perspective:

$$
\text { ويتضمن ما يأتي: }
$$

1) نظرية التحليل الذفسي theory Psychological من وجهة نظر التحليل النفسي فإن الفصام يشتق من التطور النفسي الذي ثبت في مرحلة من مراحل النهو النفسي وقبل تطور الانا [38].

نظرية هاري ستاك سوليفان يفترض سوليفان في نظريته ان جذور المرض الفصامي تنبت مما سمّاه (نكبة الصلات الشخصية) بين الفصامي وبين والديه، واشار سوليفان ان ابتعاد الفرد المصاب عن

Abdul Al-kareem, W. (2019). The impact of cognitive behavioral therapy with program (Self- Instructions). Journal Port Science Research, 2(3), 537-565. doi.org/10.36371/port.2018.02.3.11. 
الآخرين وانسحابه الى ذاته الداخلية يدل على تجنب العلاقات المؤلمة التي تربطه بالغير والتي تتضمن الانتقاد والتهديد، وتنذره بالعجز والفشل، واكد سوليفان سبب الفصام في حالة القلق الشديد الناجم عن مثل هذا الواقع الذي يكون قاعدة لحالة من فقدان الترابط في حياته النفسية [39]. 3) نظرية الشدة والارهاق تفترض هذه النظرية ان تعرض الفرد لضغوط تزيد عن حاجته وعن درجة مقدرة الفرد على تحمل وطأتها قد تؤدي الى استجابات ضارة امـا تسبب تحطيماً لأجهزة تحمله النفسي، او الى قيام تطبع غير طبيعي لا يتمكن الفرد بسببه من التعامل بكفاءة مع متطلبات

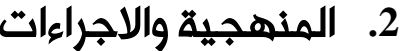

وقد اعتمدت الباحثة المنهج الاكلينيكي شبه التجريبي ذي المنحى الفردي في معالجة البيانات اتساقاً مع مشكلة البحث وأهدافه تم تحديد متغيرات البحث الحالي , اذ يعد (العلاج السلوكي المعرفي بأسلوب (التعليمات الذاتية) , متغيراً مستقلاً, والتأهيل النفسي والاجتماعي متغير تابع , ولأهمية ضبط اثر العوامل الخارجية على التجربة , فإن التجريب يتخذ تصاميم كثيرة من أجل ضبط هذا التأثير او قياسه وأخذه بالاعتبار ويتوقف اختيار التصميم التجريبي على امور منها الوقت اللازم لجمع البيانات والكلفة ونسبة المعلومات الى الكلفة وعدد المتغيرات التي يتعامل معها الباحث لاختبار صحة الفرضيات, وعدد الحالات التي هي قيد الدراسة ونوع العلاج المستعمل والوقت الذي يصرف في العلاج اي عدد الجلسات والزمن الذي تستغرقه الجلسة الواحدة [41].

اولاً: التصميم شبه التجريبي تطلب الامر نتيجة لطبيعة البحث الحالي الاستعانة بتصميم السلسلة الزمنية (Time Series Design) إذ يكون لدى الباحث في هذا التصميم حالة واحدة شبه تجريبية. ويعد هذا التصميم شبيهاً بتصميم الهجموعة الواحدة - اختبار قبلي واختبار بعدي، اذ يكون لدينا في كليهما مجموعة واحدة، ولكن استعمال قياسات كثيرة في تصميم السلاسل الزمنية قبل المعالجة وبعدها يجعل من هذا التصميم أكثر قوة من التصميم الآخر اذ ان استعمال هذه القياسات الاضافية التي تسبق وتلي المعالجة تمكن الباحث من تقدير تأثير النضح كمصدر يؤثر على الصدق الداخلي لنتائج البحث [42].

مجتمع البحث المستهدف ويعرف بأنه المجتمع الذي سيتم تعميم نتائج البحث عليه والمحصلة من العينة [43]. لذا يشمل مجتمع البحث المستهدف عدد المصابين (بالفصام المتبقي وقد تم تحديدهم من خلال قاعدة بيانات مستشفى (ابن رشد للأمراض النفسية) اذ بلغ مجموعهم (281) مراجع وهراجعة.

عبد الكريم، وفاء شاكر. (2019). تأثير العلاخ السلوكي المعرفي بأسلوب (التعليمات الذاتية) في التأهيل النفسي الفي

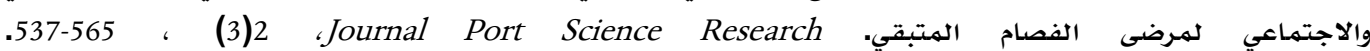


عينتا البحث (Sample of research) تم اختيار عينة البحث الحالي بشكل غرضي من مجموعة من الهرضى المراجعين لمستشفى الامراض النفسية ابن رشد المصابين باضطراب الفصام المتبقي فقط من مجموع (281) مراجع وهراجعة. يتضمن البحث الحالي عينيتين هما:

1) عينة التحليل الإحصائي والبالغ عددها (120) مصاب بالفصام المتبقي لغرض التأكد من المؤشرات صدق وثبات المقياس.

2) عينة البحث الأساسية: وتحقيقاً لأهداف البحث الحالي ينبغي تشخيص وقياس مدى التأهيل النفسي والاجتماعي عند الهرضى المصابين بالفصام المتبقي من مراجعي "مستشفى الأمراض

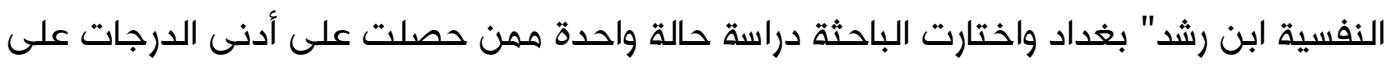
مقياس التأهيل النفسي والاجتماعي وتابعت تطورات تلك الحالة على مدى جلسات البرنامج العلاجي.

\section{Tools of research أدوات البحث}

البرنامج العلاجي: لقد أتبعت الباحثة الخطوات العلمية في بناء البرنامج العلاجي مستندةً على أسلوب مكنبوم (التعليمات الذاتية) وقد تألف البرنامج العلاجي من (17) جلسة، جلستان تمهيديتان و (13) جلسة علاجية وجلستان متابعة وقد استندت في برنامجها على الحاجات العلاجية لمتغير التأهيل النفسي والاجتماعي لمرضى الفصام المتبقي ووضعت لتلك الحاجات أهداف عامة وخاصة ثم استندت على فنيات العالم ميكنبوم في العلاج السلوكي المعرفي لأسلوب التعليمات الذاتية، وبعد تطبيق الفنيات اجرت الباحثة تقويماً بنائياً لكل جلسة.

مقياس التأهيل النفسي والاجتماعي لقد اتبعت الباحثة الخطوات العلمية في بناء المقياس وذلك تحقيقاً لأهداف البحث الحالي وكالآتي:

$$
\text { 3) }
$$

$$
\text { وقد حددت الباحثة ثلاث بدائل لكل فقرة: }
$$

(تنطبق عليَّ كثيراً - تنطبق عليَّ الى حد ما - لا تنطبق عليَّ ابداً) على التوالي إذ يكون اعلى مدى

نظري للمستجيبين على المقياس هو (90) وأقل مدى على المقياس هو (30) والوسط الفرضي (60).

صلاحية الفقرات: قد تم عرض المقياس التأهيل النفسي والاجتماعي على مجموعة من الخبراء (12)

خبير في العلوم النفسية والطب النفسي، وبعد جمع آراء المحكمين تبين أن (24) فقرة بواقع (12)

Abdul Al-kareem, W. (2019). The impact of cognitive behavioral therapy with program (Self- Instructions). Journaı Port Science Research, 2(3), 537-565. doi.org/10.36371/port.2018.02.3.11. 
فقرة لكل مجال قد نالت على نسبة أتفاق (80\%) فأكثر ولم تحصل (6) فقرات بواقع (3) في كل مجال على نسبة الاتفاق المطلوبة لذا تم حذفها من المقياس وأصبح المقياس يتألف من (24) فقرة. التجربة الاستطلاعية: لغرض معرفة مدى وضوح التعليمات وطريقة الاجابة ووضوح الفقرات ومعرفة الوقت المستغرق للإجابة على المقياس تم تطبيق المقياس على عينة من مرضى (الفصام المتبقي) من مراجعي مستشفى ابن رشد للأمراض النفسية والبالغ عددهم (20) مراجع بواقع (10) اناث و(10) ذكور تم جمعهم في حديقة المستشفى، وقد تبين أن تعليمات المقياس وفقراته كانت واضحة ومدى ابعى الوقت المستغرق تراوح من (10-20) دقيقة.

عينة التحليل الاحصائي: أختارت الباحثة عينة قوامها (120) من مرضى الفصام المتبقي من

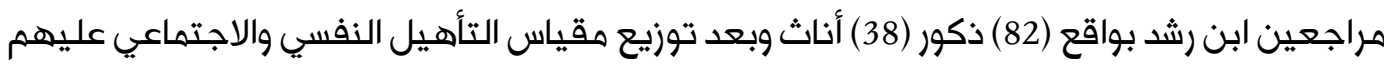
تم تصحيح المقياس بعد استجابتهم عليه ووضعت لهم درجات كلية لكل استمارة وتم استخراج القوى التمييزية بأسلوبين:

1) أسلوب الهجموعتان المتطرفتان: بعد تصحيح المقياس رتبت درجات المقياس الكلية تنازلياً من أعلى درجة إلى ادنى درجة وتم اختيار (27) ٪ من المجموعة العليا و(27)٪من الهجموعة الدنيا ، وقد بلغت استمارات المجموعة العليا (32) استمارة ونفسها في المجموعة الدنيا ، إذ كان مجموع الاستمارات في المجموعتين (64) استمارة وباستخدام الاختبار التائي لعينتين مستقلتين تبين ان جميع القيم التائية لفقرات المقياس كانت دالة احصائياً عند مستوى دلالة (0.05) ودرجة حرية (62) ولذلك عدت فقرات المقياس على وفق هذا المعيار فقرات مميزة . 2) علاقة الفقرة بالدرجة الكلية للمقياس: تم حساب معاملات الارتباط بين درجة كل فقرة مع درجة المقياس الكلية وذلك باستعمال معامل ارتباط بيرسون، وقد أتضح ان جميع معاملات الارتباط كانت دالة احصائياً لأنها اعلى من معاملات الارتباط الجدولية. 3) علاقة درجة ارتباط فقرات مجالات المقياس بالدرجة الكلية: تم احتساب معامل الارتباط بين درجة فقرات كل مجال بالدرجة الكلية باستعمال الاختبار التائي إذ كانت جميع معاملات الارتباط دالة احصائياً لدى مقارنتها بالقيمة التائية عند مستوى دلالة (0,05).

\section{مؤشرات صدق وثبات الهقياس: تم استخراج صدق المقياس بطريقتين:} 1) الصدق الظاهري: من خلال عرض المقياس على مجموعة من المحكمين والبالغ عددهم (12) لمعرفة مدى صدق المقياس، إذ تم الابقاء على (24) فقرة من خلال آراء المحكمين ونسبة الاتفاق المطلوبة لكل فقرة وكانت نسبة الاتفاق (80\%).

عبد الكريم، وفاء شاكر. (2019). تأثير العلاخ السلوكي المعرفي بأسلوب (التعليمات الذاتية) في التأهيل النفسي

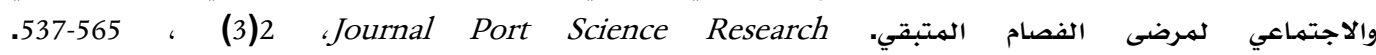


2) صدق البناء: لقد تم استخراج صدق البناء من خلال معرفة علاقة درجة الفقرة بدرجة المقياس الكلية وحساب معامل الارتباط بينهما وكذلك علاقة المجال النفسي والاجتماعي بالدرجة الكلية للمقياس وقد أتضح أن جميع فقرات المقياس دالة إحصائياً عند مستوى دلالة (0.05) ٪ ودرجة حرية (118) وقد تم الإشارة الى ذلك سابقاً.

ثبات المقياس Scale Reliability: تم حساب ثبات مقياس التأهيل النفسي والاجتماعي بطريقتين: الاختبار واعادة الاختبار تم تطبيق المقياس للمرة الأولى على عينة قوامها (20) متعالج وهتعالجة في مستشفى ابن رشد للمرضى المصابين بالفصام المتبقي وقد تم اعادة تطبيق المقياس على نفس العينة وبعد مرور اسبوعين على الاختبار الاول وتم حساب معامل الارتباط بين الاختبارين، إذ بلغ (84)٪. طريقة الاتساق الداخلي تحليل التباين باستعمال معادلة الفكرونباخ تم استعمال هذه الطريقة لاستخراج الثبات على عينة قوامها (20) متعالج ومتعالجة وتبين ان الثبات بلغ (81٪).

التطبيق النهائي: بعد حساب درجات مقياس التأهيل النفسي والاجتماعي على مرضى الفصام المتبقي تم اختيار حالة واحدة ممن حصلت على أدنى الدرجات على المقياس المذكور لغرض تطبيق البرنامج عليها بواقع (17) جلسة علاجية، جلسة واحدة لكل اسبوع. البرنامج العلاجي وفق أسلوب (التعليمات الذاتية) لميكنبوم

تصميم الخطة العلاجية: يستند عمل البرنامج العلاجي على أمرين أساسيين هما: 1) تشخيص المريض وإعراضه المرضية (وقد اعتمدت الباحثة في ذلك على تشخيص الطبيب النفسي) والحالة المرضية والمشكلات المصاحبة للاضطراب النفسي الذي يعاني منه المريض. 2) تقسيم فترة العلاج الى ثلاث مراحل والجدول (9) يوضح مراحل العلاج. جدول (1) مراحل وأهداف كل مرحلة

\begin{tabular}{|c|c|c|}
\hline نهاية العلاج & منتصف العلاج & بداية البرنامج \\
\hline منع العلاج والعمل على إنهاء & 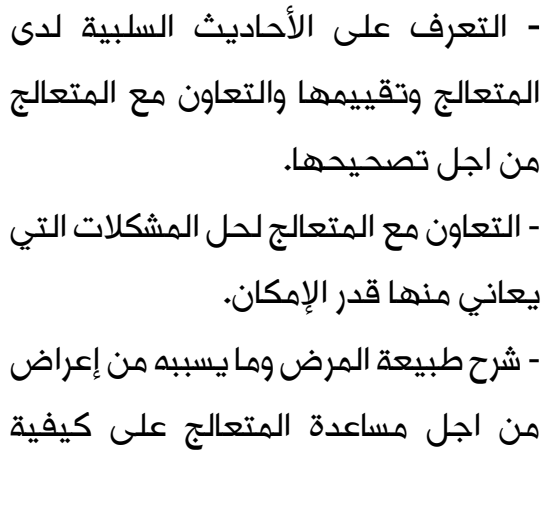 & 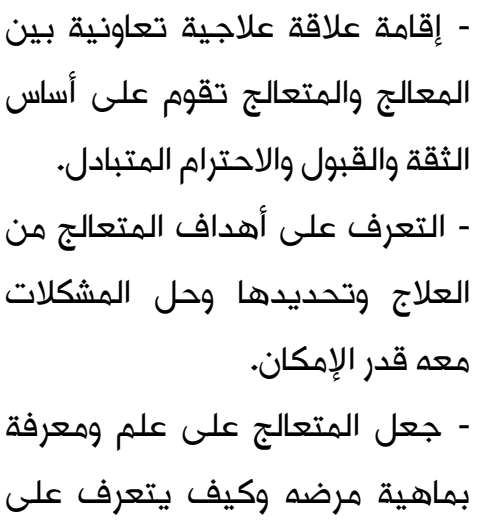 \\
\hline
\end{tabular}

Abdul Al-kareem, W. (2019). The impact of cognitive behavioral therapy with program (Self- Instructions). Journaı Port Science Research, 2(3), 537-565. doi.org/10.36371/port.2018.02.3.11. 


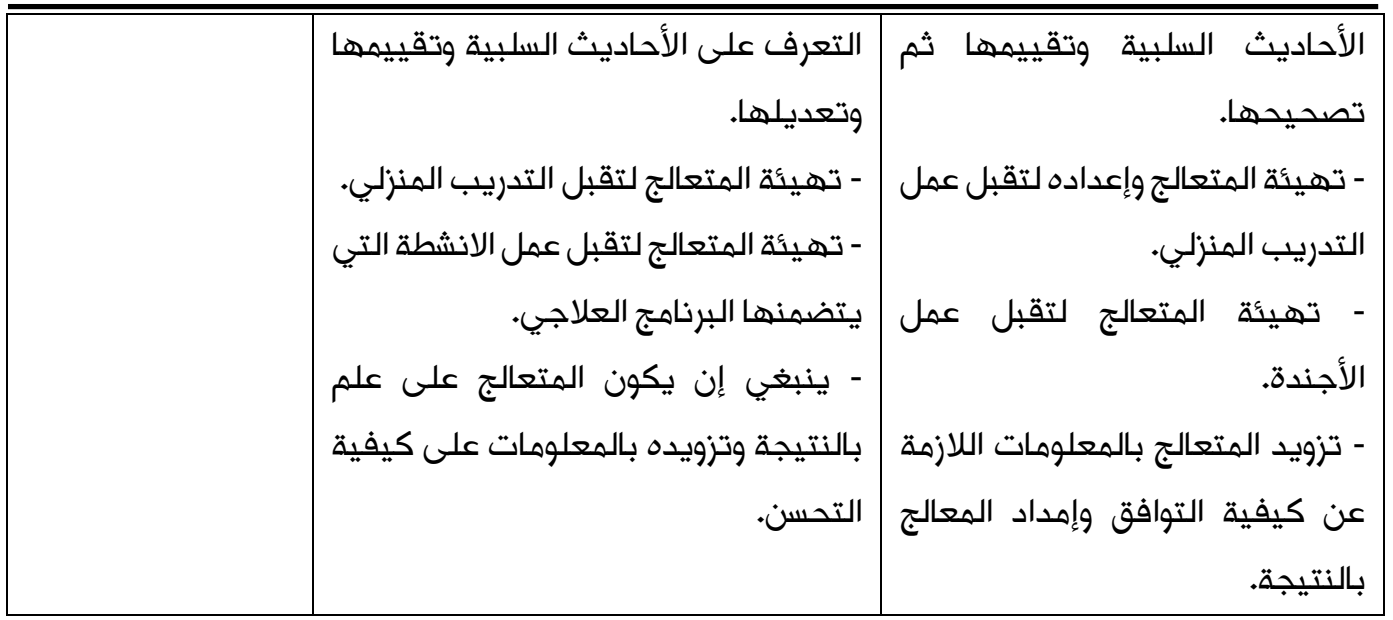

تكوين البرنامج العلاجي: يتضمن البرنامج العلاجي السلوكي المعرفي وفقاً لأنموذج ميكنبوم من (17) جلسة علاجية تشتمل على عدة مراحل وقد تم تقسيمها حسب مراحل العلاج والجدول (1) يوضح ذلك.

\section{الجدول (2) البرنامج العلاجي وفق مراحل العلاج}

\begin{tabular}{|c|c|c|}
\hline الإجراءات & عدد الجلسات & المرحلة \\
\hline لتحديد درجة سوء التأهيل النفسي والاجتماعي ومعرفة الحالة وشرح العلاج المعرفي والاتفاق على توقيع عقد العلاج لمدة 1-2 أسبوع & جلستان & مرحلة \\
\hline لفترة 3 أشهر بمعدل جلسة واحدة أسبوعيا & 13 جلسة & 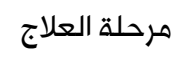 \\
\hline 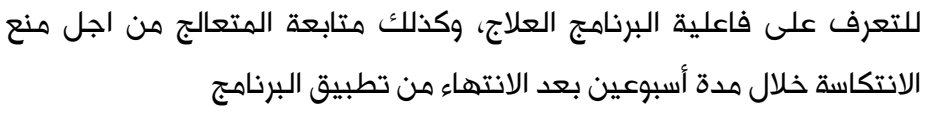 & جلستان & مرحلة المتابعة \\
\hline
\end{tabular}

أكد بعض علماء العلاج السلوكي المعرفي، أن العلاج الناجح غالباً ما تتبعه جلسات متابعة يتم الاتفاق عليها بين المعالج والمريض بحيث تكون جلسة كل (3) و(8)و(12) شهراً وذلك بهدف تعزيز وتدعيم

$$
\text { العلاج السلوكي المعرفي (بيك،2007:405). }
$$

الإطار العام لجلسات العلاج السلوكي المعرفي (C.B.T) تتخذ جلسات العلاج شكلاً متكرراً وبنوداً عدا الجلسة الأولى وكالاتي

1 ) المراجعة المستمرة لحالة المريض المزاجية.

عبد الكريه، وفاء شاكر. (2019). تأثير العلاخ السلوكي المعرفي بأسلوب (التعليمات الذاتية) في التأهيل النفسي

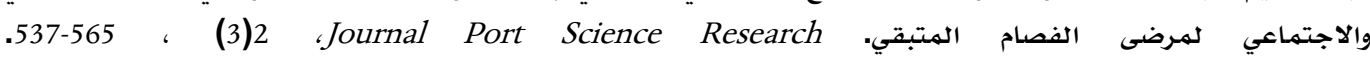


2) تهيئة الانشطة والمواضيع الخاصة بالجلسات.

$$
\text { 3) ) مراجعة التدريب المنزلي للجلسة السابقة. }
$$

6) التغذية الراجعة من خلالها يتم التعرف على استجابة المتعالج عن الجلسة والعلاج والباحثة.

الهدف العام للبرنامج: اعادة التأهيل النفسي والاجتماعي وتحسين الحوار الذاتي لتسهيل عملية الشفاء ما يعانيه المتعالج من الاعراض السالبة لمرض الفصام المتبقي ومنع الانتكاسة.

\section{الأهداف الخاصة}

$$
\text { رفع مستوى التأهيل النفسي والاجتماعي لدى المصابين بالفصام المتبقي. }
$$

أن تخفف الاعراض السالبة عن طريق ابدال الحوارات الداخلية السلبية بحوارات داخلية ايجابية

$$
\text { تساعد على تكوين أبنية معرفية جديدة. }
$$

\section{الجلستان التههيدية}

تعد الجلستان التمهيدية مهمة وأساسية في المراحل الأولى من العلاج السلوكي المعرفي ، إذ يتم من خلالها إجراء مقابلات مع المريض لتقييم وضعه ، والتعرف على المشكلات التي يعاني منها والإعراض المرضية التي يعاني منها كل فرد من إفراد العينة وكذلك استعانت الباحثة للحصول على ،لى المعلومات بواسطة الملف الطبي لكل حالة من إفراد العينة من قاعدة البيانات وتشخيص الطبيب النفسي للفرد المصاب بالفصام المتبقي الذي حددت درجته (F5.5) وفقاً للدليل التشخيصي الرابع المعدل (Dsm-IV) وأسرة الهريض ، وقد حددت الأهداف العامة من العلاج وهي:-

1) إقامة علاقة علاجية تعاونية مع المريض قائمة على الثقة والاحترام المتبادل. 2) شرح طبيعة العلاج السلوكي المعرفي وفق أنموذج ميكنبوم (michinbume) والعملية العلاجية. 3) غرس الأمل في نفس المتعالج وتفهم مشكلاته وإفهامه بأن الإعراض التي يعاني منها هي هودي إعراض مرضية. 


\begin{tabular}{|c|c|}
\hline $\begin{array}{l}\text { J. port. sci. res. } \\
\text { ISSN : } 2616-744 \text { (Online) } \\
\text { ISSN : 2616-6232(Print) } \\
\text { ISSN 2616-7220 (USB) }\end{array}$ & (1) (2) OPEN Caccess \\
\hline التفصيلات & المفردات \\
\hline - الحاجة - الحاجة الى تنمية القدرة على التفاعل الاجتماعي مع الآخرين. & الحاجات \\
\hline تنمية قدرة المتعالج على تقبل الآخرين & الهدف العام \\
\hline - إن - إن يتمكن من التخلص من العزلة الاجتماعية. & الأهداف \\
\hline - المناقشة - التعليمات الذاتية - التأمل - التخيل -التغذية الراجعة - التعزيز الهادي والمعنوي & المستعملة التيات \\
\hline 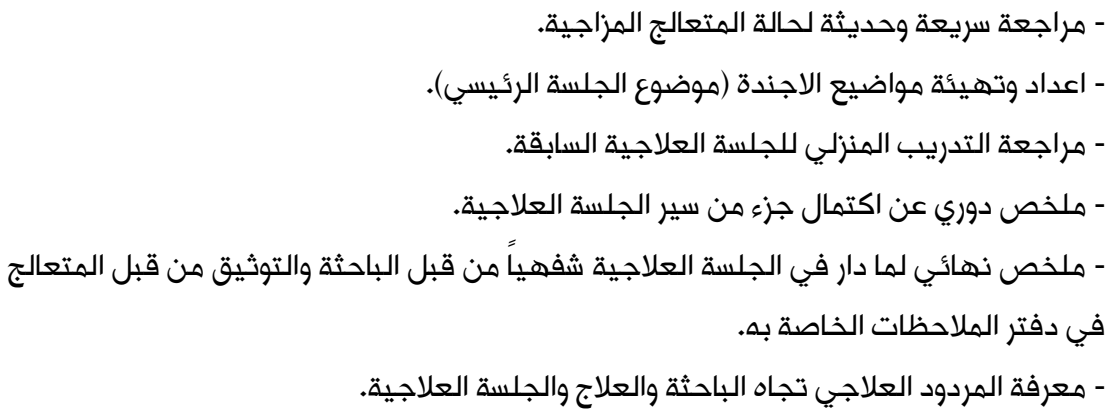 & بنود الاجندة \\
\hline - تطبيق مهارة التفاعل الاجتماعي في مواقف الحياة الهختلفة سواء داخل الأسرة أو خارجها مثل & التدريب المنزلي \\
\hline
\end{tabular}

إدارة الجلسة التاسعة

• الترحيب بالهتعالج وتبادل السلام معه من قبل الباحثة ثم بعد ذلك مراجعة التدريب المنزلي للجلسة السابقة وذلك تأكيداً لأهميته واعتباره جزءاً أساسيا من العلاج مع تقديم هـئ الدعم والتشجيع من قبل الباحثة باستعمال (التغذية الراجعة) مع تقديم التعزيز المادي للمتعالج الذي أنجز

$$
\text { الواجب مثل (تناول بعض العصائر أو الحلويات). }
$$

تقوم الباحثة بتقديم المعلومات الضرورية لتوضيح مفهوم (تقبل الآخرين) وأهميته في حياتنا لإشباع كثير من حاجاتنا النفسية وان هذه العلاقات ينبغي إن تقوم على المحبة والاحترام المتبادل من اجل التخلص من التمركز حول الذات لان المتعالج عندما يدرك هذه المعاني يزيد من دافعيته نحو الانتماء الى جماعة معينة يؤثر ويتأثر بهم. تقوم الباحثة باستعمال تقنية (التعليمات الذاتية) في إعادة التأهيل النفسي والاجتماعي في تقبل الآخرين وكما في المثال التالي (اشعر إني مكروه من قبل الآخرين) إن هذه الفكرة تعيق (تقبل الآخرين) توجه الباحثة التعليمات الى ذاتها بصوت مسهوع ثم بصوت منخفض للتدقيق في الفكرة إمام المتعالج والطلب منه ترديد ذلك لغرض التدريب وباستعمال تقنيتي (التأمل عبد الكريه، وفاء شاكر. (2019). تأثير العلاخ السلوكي المعرفي بأسلوب (التعليمات الذاتية) في التأهيل النفسي

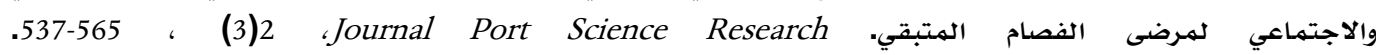


والتخيل) يتم التوصل الى الاستجابة الصحيحة وتغيير الحديث السلبي الى ايجابي والعمل على تثبيت الاستجابة عن طريق التكرار. تطلب الباحثة من الهتعالج استعمال تقنية (التعليمات الذاتية) في اعادة التأهيل النفسي والاجتماعي وتتابع سير التعليمات الذاتية لتحقيق الهدف من الجلسة باستعمال تقنية (التغذية الراجعة). قدمت الباحثة للمتعالج رسم بياني عن سير التحسن لحالة النفسية وفقاً لنتائج البحث ومقياس الشدة للغضب والتوتر، ان الهدف من عرضه في هذه الجلسة من اجل تقديم دليل على تحسن حالته النفسية مع تقديم معلومات وشرح عن اضطراب الفصام المتبقي. ملخص عن اكتمال جزء من سير الجلسة العلاجية بالتعاون مع المتعالج. ملخص عام ونهائي لها دار في الجلسة العلاجية شفهياً من قبل الباحثة مع التوثيق من قبل هن المتعالج وبكلماته نفسها. تعيين التدريب المنزلي وذلك الطلب من المتعالج تطبيق مهارة تقبل الاخرين على مواقف حياتية مختلفة مثل المشاركة مع الاسرة في الاعداد لمناسبة ما، او زيارة صديق. تعيين موعد زمان ومكان الجلسة القادمة.

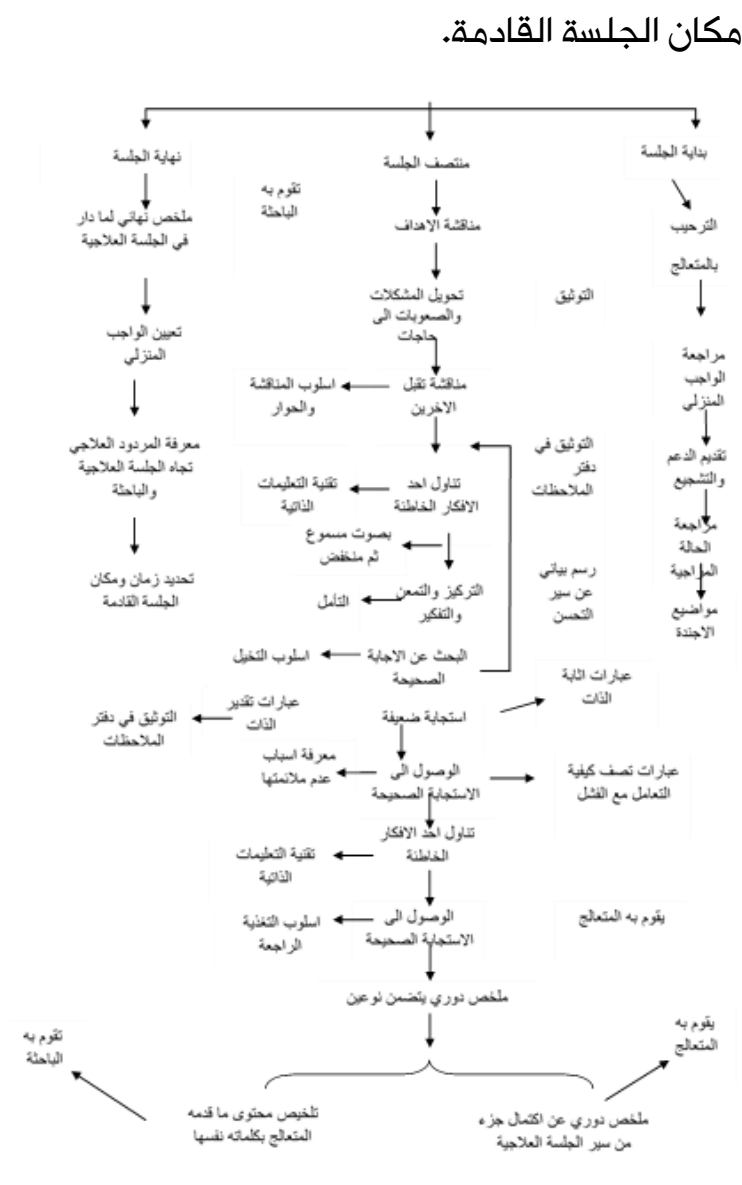

مخطط (1) يوضح سير الجلسة

Abdul Al-kareem, W. (2019). The impact of cognitive behavioral therapy with program (Self- Instructions). Journai Port Science Research, 2(3), 537-565. doi.org/10.36371/port.2018.02.3.11. 
1) قياس التأهيل النفسي والاجتماعي لهرض الفصام المتبقي باستعمال اداة البحث. 2) التعرف على المواقف والأحداث التي يواجها المتعالج وكيفية تطبيقه لمهارات العلاج السلوكي بلي

$$
\text { المعرفي. }
$$

3) مراجعة التدريب المنزلي بالاشتراك بين المتعالج والباحثة. 4) تقديم الدعم والتشجيع المادي والمعنوي للمتعالج.

\section{الاجراءات التي تم اتخاذها في سير الجلستين وكالاتي}

1) الترحيب بالمتعالج وهراجعة التدريب الهنزلي التي تتضمن (مراقبة الاعراض، وهراجعة دفتر

$$
\text { الملاحظات). }
$$

2) ت تطبيق اداة البحث.

3) عرض رسم بياني عن حالة المتعالج يوضح سير التحسن مع تقديم التوضيحات والتفسيرات

$$
\text { والمعلومات اللازمة من قبل الباحثة. }
$$

4) الاستماع لشرح المتعالج للمواقف والاحداث الحياتية المختلفة التي تعرض لها للتعرف على كيفية ممارسة وتطبيق مهارات العلاج السلوكي المعرفي التي اكتسبها خلال الجلسات العلاجية. 5) مناقشة ومراجعة اهم الموضوعات التي تم مناقشتها خلال الجلسات (13) وقد اعطت الباحثة للمتعالج الحرية في ترتيب المواضيع حسب اهميتها بالنسبة له.

6) قسم المتعالج المشكلات التي من المحتمل أن يتعرض لها مستقبلاً ضمن مجموعات ليسهل

$$
\text { تناولها ثم حلها. }
$$

7) اعادت الباحثة شرح (اسلوب التعليمات الذاتية) للمتعالج ووضحت له كيفية استعماله وطلبت منه تطبيق هذا الاسلوب من خلال حل مشكلة افتراضية طرحتها الباحثة. 8) طلبت الباحثة من المتعالج ان يذكر اهم الاساليب التي سيلجأ اليها في حالة تعرضه لانتكاسة في المستقبل وكيفية تطبيقه لها وكيف سيواجه اعراض الفصام المتبقي. 9) من أجل التأكد من قدرة المتعالج على تطبيق التقنيات العلاجية بصورة صحيحة، تم تعريض المتعالج لأحدى مشكلات سوء التأهيل النفسي والاجتماعي ثم طبقت عليها الباحثة تقنية (التعليمات الذاتية) ثم طلبت منه تطبيق تقنية التعليمات الذاتية للاطمئنان من قابلية المتعالج على تطبيق المهارات العلاجية بصورة صحيحة والاستفادة منها مستقبلاً في حال تعرضه لأي 


\section{استمرار الباحثة على تقديم الدعم والتشجيع للمتعالج والثناء عليه وتقديم الشكر له.}

ملاحظة: الباحثة اكتفت بعرض (5) جلسات (الجلستان التههيديتان وجلسة علاجية واحدة وجلستا المتابعة) من البرنامج العلاجي المكون من (17) جلسة وبإمكان الدارسين والراغبين بتطبيق البرنامج العلاجي مفاتحة الباحثان لغرض استلام نسخة كاملة من البرنامج.

\section{3. التحليل وعرض النتائج}

سيتم عرض نتائج البحث ومناقشتها على وفق الأهداف المحددة كما يأتي: 1) قياس التأهيل النفسي والاجتماعي لمرضى الفصام المتبقي.

2) التعرف على تأثير العلاج السلوكي المعرفي بأسلوبي (التعليمات الذاتية) في التأهيل النفسي والاجتماعي لدى الهرضى المصابين بالفصام المتبقي. وذلك من خلال التحقق من الفرضية

$$
\text { الآتية: }
$$

لا توجد فروق ذات دلالة احصائية في التأهيل النفسي والاجتماعي لدى المرضى المصابين بالفصام المتبقي قبل تطبيق البرنامج العلاجي وأثناءه وخلال مدة المتابعة (Follow-up) على وفق اسلوب (التعليمات الذاتية) للعالم ميكنيوم لمتعالج واحد.

ولأجل اختبار صحة الفرضيات تم استعمال الاختبار التائي لعينة واحدة لدلالة الفروق بين المتوسط المحسوب والمتوسط النظري في مقياس التأهيل النفسي والاجتماعي والجدول (3) يوضح النتائج. الجدول (3) الاختبار التائي لعينة واحدة لدلالة الفروق بين المتوسط المحسوب والمتوسط النظري في مقياس

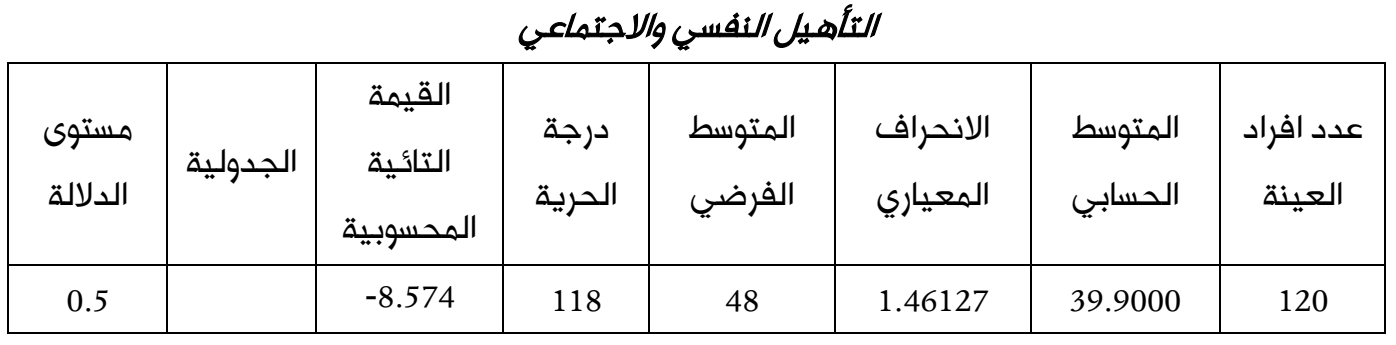

يتضح من الجدول اعلاه ان الوسط الحسابي أقل من الوسط الفرضي وهذا يدل على انخفاض درجة التأهيل الذفسي والاجتماعي لدى المرضى الهصابين بالفصام المتبقي.

Abdul Al-kareem, W. (2019). The impact of cognitive behavioral therapy with program (Self- Instructions). Journaı Port Science Research, 2(3), 537-565. doi.org/10.36371/port.2018.02.3.11. 
التعرف على تأثير العلاجي السلوكي المعرفي بأسلوب (التعليمات الذاتية) في التأهيل النفسي

والاجتماعي لدى المرضى المصابين بالفصام المتبقي. وذلك من خلال التحقق من الفرضية الاتية: أ. لا توجد فروق ذات دلالة احصائية في التأهيل النفسي والاجتماعي قبل تطبيق البرنامج العلاجي واثناءه وخلال مدة المتابعة للمتعالج.

تمثل الاجابة على الفرضية (أ) للمتعالج من خلال الجداول والاشكال البيانية والتي توضح درجاته على اداة البحث من خلال مراحل البحث (مرحلة التشخيص والعلاج والمتابعة) وتوضح الجداول (4) و (5) و(6) درجات مقياس التأهيل النفسي والاجتماعي عند تطبيقها في مراحل التشخيص والعلاج والمتابعة على التوالي، والاشكال (1) و(2) و(3) و(4و (5) توضح سير التحسن للمراحل الثلاثة (التشخيص والعلاج والمتابعة) على التوالي. لمراحل البحث الثلاثة.

الجدول (4) درجات مقياس التأهيل النفسي والاجتماعي للمتعالج الاول خلال مرحلة التشخيص

\begin{tabular}{|c|c|c|c|}
\hline العنوان & P-S-R-M & 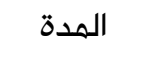 & الهرحلة التشخيص \\
\hline الجلسة التمهيدية الاولى & 24 & الاسبوع 1 & الاولى \\
\hline الجلسة التهـهيدية الثانية & 24 & الاسبوع 2 & الثانية \\
\hline
\end{tabular}

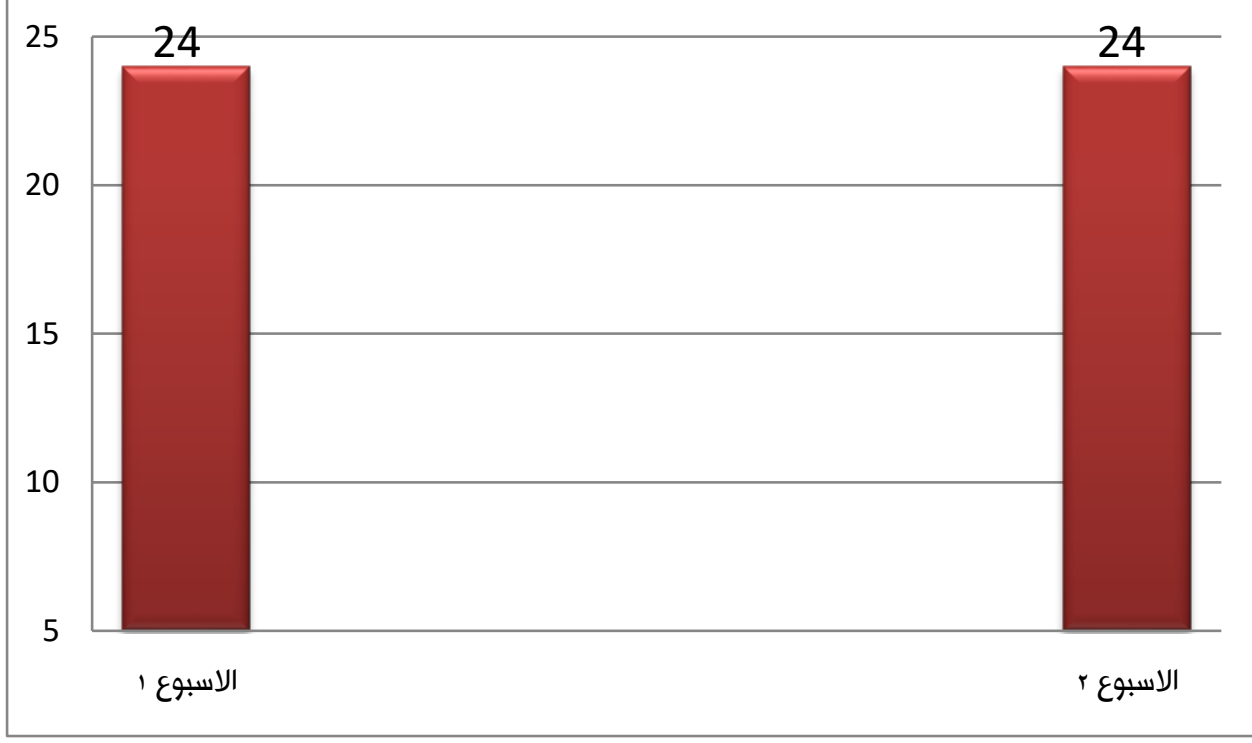

شكل (2) يوضح درجات المتعالج الأول خلال مرحلة التشخيص

مرحلة التشخيص: - م

عبد الكريه، وفاء شاكر. (2019). تأثير العلاخ السلوكي المعرفي بأسلوب (التعليمات الذاتية) في التأهيل النفسي

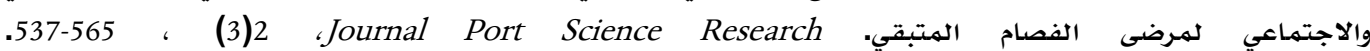


من الجدول (5) وشكل (2) يمكن ملاحظة درجة مقياس التأهيل النفسي والاجتماعي للمتعالج الاول والملاحظ للجدول والشكل التابع له نجد ان القيمتين قد اتخذت درجات ثابتة نسبيا خلال مرحلة التشخيص.

مرحلة العلاج: امتدت فترة العلاج لمدة (13) اسبوعيا والجدول (5) وشكل (3) و(4) يوضح: 1) ان درجة مقياس التأهيل النفسي والاجتماعي للمتعالج الاول كانت (24) على الاختبار القبلي. 2) يوضح شكل (6) ان درجة التأهيل النفسي والاجتماعي بقيت ثابتة في ثلاث جلسات الاولى ثم ارتفعت في الاسبوع الرابع والاخير من الشهر الاول بمقدار ثلاث درجات (27) واستمر التغيير في الدرجة في الشهر الثاني والثالث اي بهجموع (3) درجات في الشهر الاول و (11) في الشهر الثاني و (7) درجات في الشهر الثالث و(3) درجات في الاسبوع (13) ويرافق هذا الارتفاع في الدرجة على اداة البحث تحسن في الاعراض السالبة لدى الفرد المتعالج الذي يؤدي بدوره الى حسن التأهيل النفسي والاجتماعي. وهذا يحقق هدف البحث الحالي الرئيسي. الجدول (5) درجات المتعالج على مقياس التأهيل الثفسي والاجتماعي خلال مرحلة العلاج

\begin{tabular}{|c|c|c|}
\hline p-s-r-m & المدة & مرحلة العلاج \\
\hline $\begin{array}{l}24 \\
24 \\
24 \\
27\end{array}$ & الاسبوع الاسبوع 1 الاسبوع 3 & الشهر الاول \\
\hline $\begin{array}{l}30 \\
33 \\
35 \\
38\end{array}$ & الاسببوع الاسبوع 5 الاسبوع 7 الاسبوع 8 & الشهر الثاني \\
\hline $\begin{array}{l}41 \\
38 \\
41 \\
44\end{array}$ & الاسببوع الاسبوع 9 الاسبوع 10 & الشهر الثالث \\
\hline 47 & الاسبوع 13 & الشهر الرابع \\
\hline
\end{tabular}




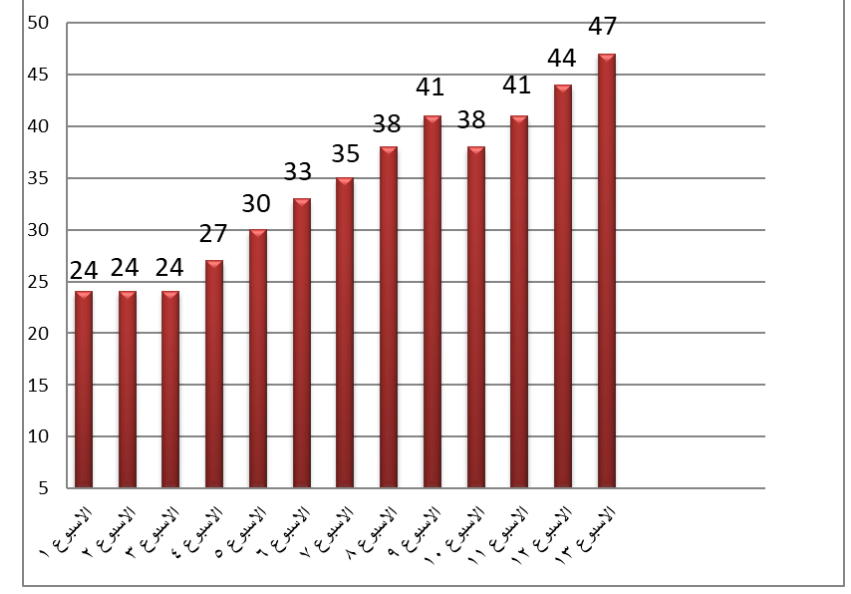

شكل (3) يوضح درجات المتعالج على أداة البحث خلال مرحلة العلاج

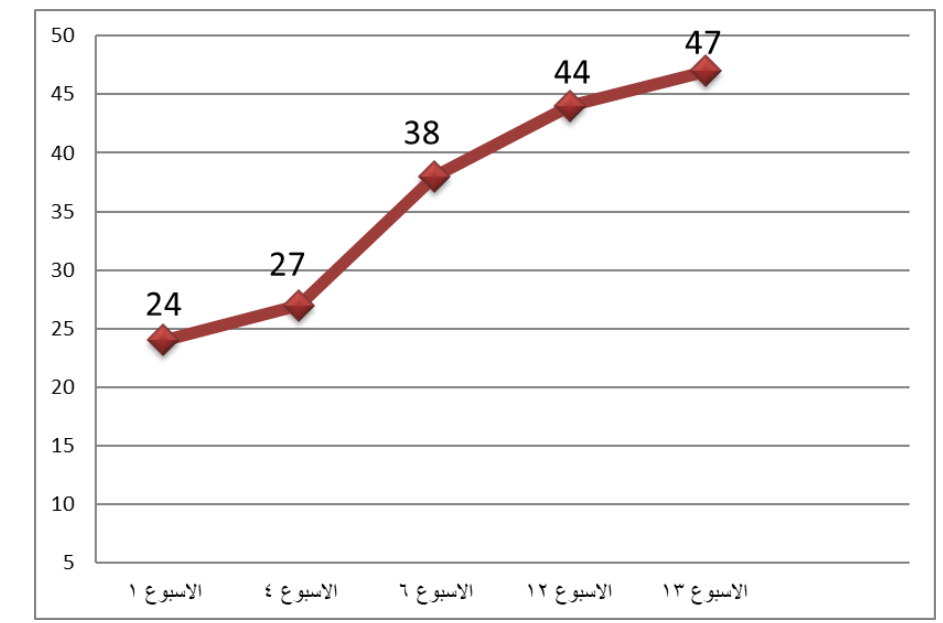

\section{شكل (4) يوضح سير التحسن للمتعالج على أداة البحث خلال مرحلة العلاج}

مرحلة المتابعة: مدتها اسبوعين وقد تم تقسيمها الى مرحلتين للتأكد من سير التحسن، ويوضح جدول (32) وشكل (5) و(6) فاعلية البرنامج العلاجي مقدرا بدرجات المتعالج على اداة البحث والجدول (6) يوضح درجات المتعالج خلال مرحلة المتابعة الاولى.

الجدول (6) يوضح درجات المتعالج خلال مرحلة المتابعة

\begin{tabular}{|c|c|c|}
\hline p-s-r-m & المدة & هرحلة المتابعة \\
\hline 50 & الاسبوع 1 & الاولى \\
\hline 50 & الأسبوع 2 & الثانية \\
\hline
\end{tabular}

عبد الكريم، وفاء شاكر. (2019). تأثير العلاخ السلوكي المعرفي بأسلوب (التعليمات الناتية) في التأهيل النفسي والاجتماعي لمرضى الفصام المتبقي. Journal Port Science Research، 


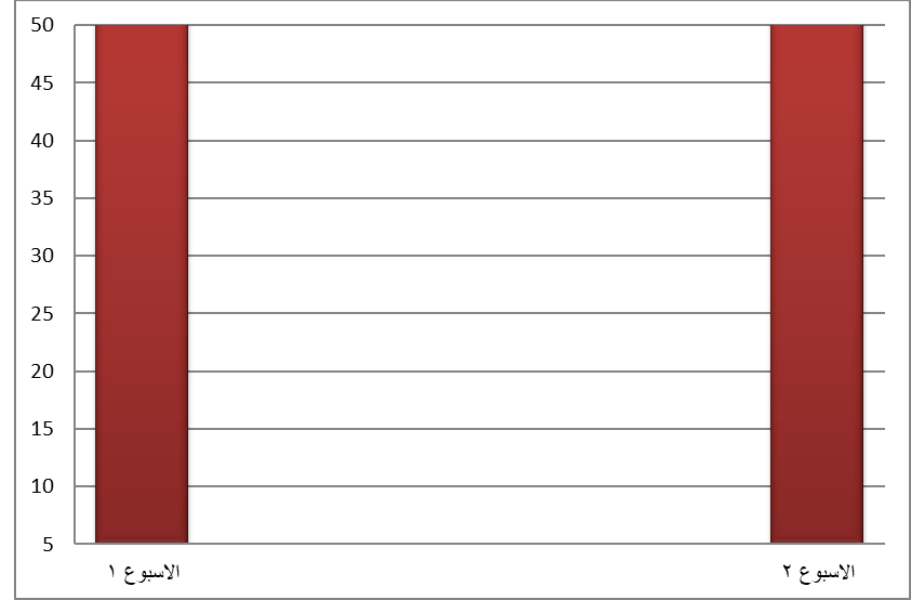

شكل (4) يوضح درجات المتعالج على أداة البحث خلال مرحلة المثابعة يلاحظ من الجدول (6) وشكل (5) الثابع

1) ان التأهيل النفسي والاجتماعي ارتفع بعد انتهاء البرنامج العلاجي وخلال مدة المتابعة اذ بلغ حوالي (50) درجة على مقياس التأهيل النفسي والاجتماعي لان المتعالج استفاد من مهارات العلاج وتمكن من تطبيقها خلال الجلسات والتي استدل عليها من تقييم الباحثة للتدريبات المنزلية خلال فترة المتابعة مما ساعد على احلال الاحاديث الداخلية الصحية بدل الاحاديث المختلة وظيفيا وهذا يتفق مع الخطوات الرئيسية لنظرية ميكنبوم حول تغيير الابنية المعرفية القديمة واحلال محلها ابنية معرفية جديدة الذي يؤدي بدوره الى التأثير على الاحاديث الداخلية

$$
\text { المختلة وظيفيا وابدالها بأحاديث ايجابية . }
$$

2) اتفقت نتائج مرحلة العلاج مع نتائج دراستي ظافر 2011 وهانك وجونس 1983 من أن العلاج السلوكي المعرفي يعد علاجا مكملا واساسيا في تعديل الأحاديث السلبية وخفض السلوك اللاتكيفي واكتساب المهارات.

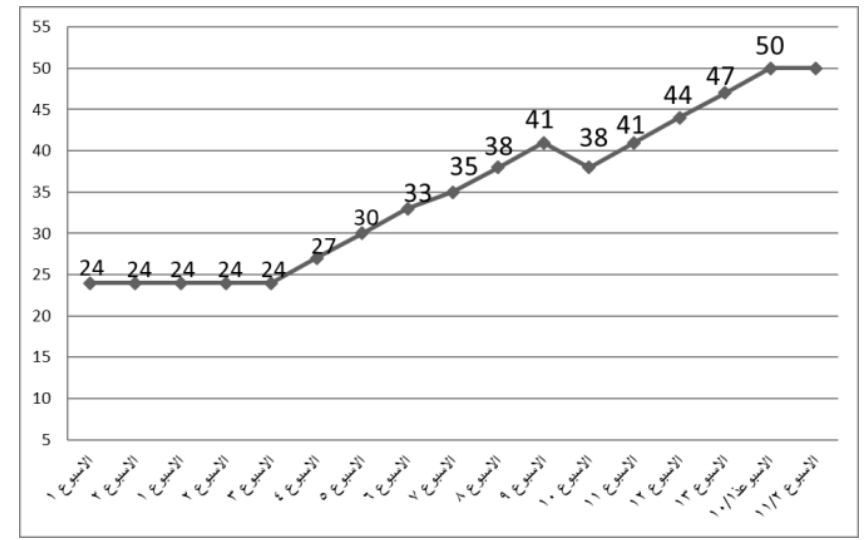

شكل (6) يوضح سير التحسن في التأهيل النفسي والاجتماعي خلال مرحلة البحث الثلاثة

Abdul Al-kareem, W. (2019). The impact of cognitive behavioral therapy with program (Self- Instructions). Journa Port Science Research, 2(3), 537-565. doi.org/10.36371/port.2018.02.3.11. 
في ضوء ما تم عرضه من نتائج اعتمد فيها بشكل اساس على القياس البصري لهنحنيات القيم على مقياس التأهيل النفسي والاجتماعي خلال مراحل البحث الثلاثة (التشخيص والعلاج والهتابعة) تم

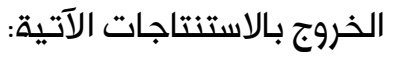

1) أن اسلوب (التعليمات الذاتية) للعالم ميكنبوم وما يتضمنه من النشاطات والفعاليات يعد هو الآخر اسلوباً علاجياً ذا فاعلية يمكن استعماله في التأهيل النفسي والاجتماعي لمرضى الفصام المتبقي وأفضل خيار علاجي للتخفيف من حدة الاعراض السالبة لدى المصابين بالفصام

أن نجاح هذا الاسلوب في التأهيل النفسي والاجتماعي للمرضى المصابين بالفصام المتبقي يعد تجربة ناجحة تؤكد على ضرورة الاهتمام بفئة تشكل نسبة كبيرة من نزلاء المستشفيات حكم عليها بأنها فئة غير قابلة للشفاء. 3) أن الاعراض السالبة لدى مرضى الفصام المتبقي هي اعراض قابلة للتغيير والتعديل إذا ما استعملت معها برامج علاجية تستند الى أطار نظري علمي للاعتماد عليه في هذا التغيير او التعديل.

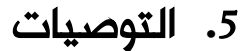

مناشدة وزارتي التعليم العالي والصحة الى ارسال بعض المختصين في الصحة النفسية والطب النفسي في دورات تدريبية خارج العراق لزيادة تدريبهم في العلاج السلوكي المعرفي. 2) على وزارتي التعليم العالي والصحة الاهتمام بالعلاج السلوكي المعرفي في الجامعات العراقية وهراكز الاسناد الففسي التابع لوزارة الصحة وإعطائها الرعاية الكافية لاستعمال هذا البرنامج العلاجي لتحسين التأهيل النفسي والاجتماعي للمصابين من المرضى النفسانيين.

$$
\text { استكمالاً لنتائج البحث الحالي إجراء الدراسات الآتية: }
$$

1) إجراء دراسة نفسها على عينات أخرى لمرضى الفصام في محافظات العراق الأخرى للتأكيد

$$
\text { على نجاح الأسلوب العلاجي. }
$$

2) اعتماد الاسلوب العلاجي لميكنبوم في مستشفيات وزارة الصحة كعلاج مكمل وأساسي في

$$
\text { العلاج الدوائي. }
$$

عبد الكريم، وفاء شاكر. (2019). تأثير العلاخ السلوكي المعرفي بأسلوب (التعليمات الذاتية) في التأهيل النفسي الفيل

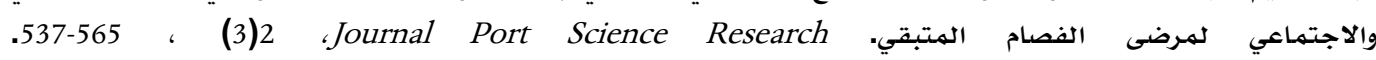


3) الاستفادة من مقياس التأهيل النفسي والاجتماعي في المراكز والوحدات الارشادية في

$$
\text { الجامعات العراقية لتشخيص طلبة الجامعة على وفق ذلك المقياس. }
$$

4) استعمال مقياس التأهيل النفسي والاجتماعي للمصابين بالاضطرابات النفسية الاخرى

$$
\text { لتحديد شدتها. }
$$

\section{References}

$$
\begin{aligned}
& \text { [1] غانم ، محمود حسن. (2006). الاضطرابات النفسية والعقلية والسلوكية. ط1، مكتبة الانجلو المصرية، } \\
& \text { القاهرة، ص 334. } \\
& \text { [2] كهال ، علي. (1987). فصام العقل او الشيزوفرينيا. الطبعة الاولى، دار واسط، لندن، ص } 39 . \\
& \text { [3] الهابط, محمد السيد. (1987). التكيف والصحة النفسية. ط2 , المكتب الجامعي الحديث، الاسكندرية، ص } \\
& \text { [4] محمود, محمد مهدي. (1985). الصحة النفسية. وزارة التربية، بغداد.13. } \\
& \text { [5] محمد ، عادل عبد الله. (2000). العلاخ المعرفي السلوكي. اسسه وتطبيقاته، القاهرة، دار الرشاد، ص24. } \\
& \text { [6] كفافي ، علاء الدين. (1999). الارثاد النفسي والعلاخ النفسي الاسري. المنظور النفسي الاتصالي، ط1، دار } \\
& \text { الفكر العربي، القاهرة، ص 127. }
\end{aligned}
$$

Walters, L. H., \& Corey, G. (1980). Theory and Practice of Counseling and [7] Psychotherapy. Family Relations, 29(1), 133. https:// doi.org/10.2307/583738

Williamson, D. A., White, M. A., York-Crowe, E., \& Stewart, T. M. (2004, November). [8] Cognitive-behavioral theories of eating disorders. Behavior Modification. https://doi.org/10.1177/0145445503259853

[9] الهاشهي، عبد الحميد محمد. (1986). التوجيه والارشاد النفسي. ط1، دار الشروق، جدة، السعودية، ص

[10] الحنفي عبد المنعم. (1991). مؤسسة التحليل النفسي. مكتبة مدبولي، القاهرة، مصر، ص 253.

Freeman, A., Davis, D. D., \& DiTomasso, R. A. (1992). Cognitive therapy of personality [11] disorders. Progress in Behavior Modification. https:// doi.org/10.1176/ajp.149.3.402

Robinson, T. R., \& Smith, S. W. (1997). Cognitive Behavior Modification. Intervention [12] in School and Clinic, 33(1), 63-64. https:// doi.org/10.1177/105345129703300113

[13] ابو أسعد, أحمد وعربيات, أحمد. (2009). نظريات الارشاد النفسي والتوجيه التربوي. ط1 , دار المسيرة للنشر

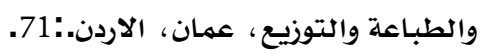

45: [14 زهران، حامد عبد السلام. (1978). الصحة والعلاخ النفسي. ط2، عالم الكتب، القاهرة

Abdul Al-kareem, W. (2019). The impact of cognitive behavioral therapy with program (Self- Instructions). Journaı Port Science Research, 2(3), 537-565. doi.org/10.36371/port.2018.02.3.11. 
[15] الحبيب ، طارق بن علي. (2013). الفصام. مؤسسة حورس الدولية، الاسكندرية: 95.

Kingdon, D., \& Mander, H. (2015). Cognitive Behavioral Therapy. In International [16] Encyclopedia of the Social \& Behavioral Sciences: Second Edition (pp. 30-32). Elsevier Inc. https:// doi.org/10.1016/B978-0-08-097086-8.27011-6

[17] محمد، عادل عبدالله. (1999). العلاخ المعرفي السلوكي. اسس وتطبيقات، دار الرشاد، الزقازيق، مصر: 60.

Murphy, R., Straebler, S., Cooper, Z., \& Fairburn, C. G. (2010). Cognitive behavioral [18] therapy for eating disorders. Psychiatric Clinics of North America, 33(3), 611-627. https:// doi.org/10.1016/j.psc.2010.04.004

Beck, A. T. (1976). Cognitive therapy and the emotional [19] disorders. INT.UNIV.PRESS, NEW

YORK.

https:// doi.org/10.1176/appi.psychotherapy.1977.31.4.633

Robinson, T. R., \& Smith, S. W. (1997). Cognitive Behavior Modification. Intervention [20] in School and Clinic, 33(1), 63-64. https:// doi.org/10.1177/105345129703300113

[21] باترسون. (1990). نظريات الارشاد والعلاخ النفسي. ترجمة: د. حامد عبد العزيز الفقي، خ2 , ط1, دار القلم للطباعة والنشر والتوزيع، الكويت: 122.

Cary, G. L. (1994). Cognitive-Behavioral Treatment of Borderline Personality [22] Disorder. American Journal of Psychotherapy, 48(1), 155-156. https:// doi.org/10.1176/appi.psychotherapy.1994.48.1.155 [23] بطرس، حافظ. (2008). المشكلات النفسية وعلاجها. دار الميسرة للنشر والتوزيع، عمان الاردن. 180-181.

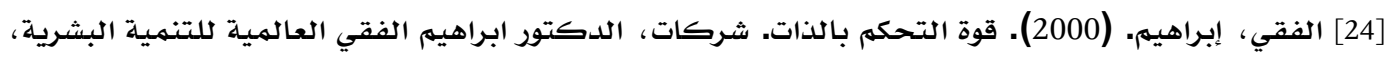

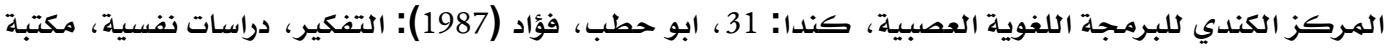
الانجلو المصرية، القاهرة: 23.

[25] التميمي، محمود كاظم محمود. (2016). ارشاد الازمات. ط1 , مركز ديبو لتعليم التفكير، عمان، الاردن.: .276

[26] التميمي، محمود كاظم والدفاعي. كاظم علي هادي. (2010). الصحة النفسية. مكتب زاكي للطباعة، بغداد: 28 (28. [27] الهاشمي، عبد الحميد محمد. (1986). التوجيه والارشاد النفسي. الصحة النفسية الوقائية، ط1، دار

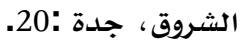
[28] العزة، سعيد وعبد الهادي. جودت. (1999). نظريات الارشاد والعلاخ النفسي، دار الثقافة للنشر والتوزيع،

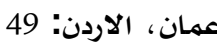
[29] شلتز , داون. (1983). نظريات الشخصية. ترجمة حمه ولي الكربولي وعبد الرحمن القيسي، مطبعة جامعة

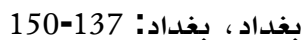

[30] هول, كالفن. س وليندي، جاردنز. (1969). نظريات الشخصية. ترجمة: فرخ أحمد وآخرون، الهيئة المصرية

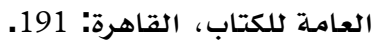

عبد الكريم، وفاء شاكر. (2019). تأثير العلاخ السلوكي المعرفي بأسلوب (التعليمات الذاتية) في التأهيل النفسي

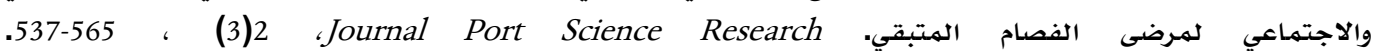
doi.org/10.36371/port.2018.02.3.11. 
[31] عباس, فيصل. (1982). الشخصية في ضوء التحليل النفسي. دار المسيرة، بيروت: 64.

ICD-10. (2014). In Practical Predictive Analytics and Decisioning Systems for Medicine: [32] Informatics Accuracy and Cost-Effectiveness for Healthcare Administration and Delivery Including Medical Research (pp. 106-115). Elsevier Inc https: / / doi.org/10.1177/1071100715600286

GUZE, S. B. (1995). Diagnostic and Statistical Manual of Mental Disorders, 4th ed. (DSM- [33] IV). American Journal of Psychiatry, 152(8), $1228-1228$ https: / / doi.org/10.1176/ajp.152.8.1228

Walters, L. H., \& Corey, G. (1980). Theory and Practice of Counseling and [34] Psychotherapy. Family Relations, 29(1), 133. https:/ / doi.org/10.2307/ 583738

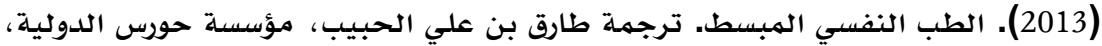

Scheid, T. (2001). Handbook of the sociology of mental health. Social Science \& Medicine, [36] 53(4), 551-552. https:// doi.org/10.1016/s0277-9536(00)00354-3

Laberge, D. (1994). Hilgard's Introduction to Psychology. Psychological Science, 5(4), [37] 184-185. https: / / doi.org/10.1111/j.1467-9280.1994.tb00496.x

Cabaniss, D. L., Cherry, S., Douglas, C. J., \& Schwartz, A. (2010). Psychodynamic [38] Psychotherapy: A Clinical Manual. Psychodynamic Psychotherapy: A Clinical Manual. John Wiley and Sons. https: / / doi.org/10.1002/9780470711262

Salgado, A., \& Salgado, A. (2010). Theories of Personality. In Introductory Psychology [39] for Nursing and Allied Health Sciences (pp. 195-195). Jaypee Brothers Medical Publishers (P) Ltd. https:// doi.org/10.5005/jp/books/11135_13

Lunn, B. (2017). Schizophrenia. In Psychiatry by Ten Teachers, Second Edition (pp. 102- [40] 113). CRC Press. https:// doi.org/10.1201/9781315380612

[41] التميمي ، محمود كاظم. (2009). كيف تكتب بحثاً أو رسالة ماجستير. دار الكتب والوثائق، بغداد: 108.

Miller, W., \& Pellen, R. M. (2012). Libraries within their institutions: Creative [42] collaborations. Libraries within their Institutions: Creative Collaborations (pp. 1-230). Taylor and Francis. https: / / doi.org/10.4324/9780203051115

[43] البطث، محمد وليد. وأبو زين، فريد كامل. (2007). مناهج البحث العلمي تصميه البحث والتحليل الاحصائي. ط1 ، جامعة عمان العربية للدراسات العليا ، توزيع دار المسيرة للطباعة والنشر والتوزيع، عمان، الاردن:

[44] جلال، أحمد سعيد. (2008). مبادئ الاحصاء النفسي. الدار الدولية للاستثمارات الثقافية، القاهرة، مصر: 